\title{
NMR structure of a $4 \times 4$ nucleotide RNA internal loop from an $R 2$ retrotransposon: Identification of a three purine-purine sheared pair motif and comparison to MC-SYM predictions
}

\author{
YELENA V. LERMAN, ${ }^{1}$ SCOTT D. KENNEDY, ${ }^{2}$ NEELAABH SHANKAR, ${ }^{2}$ MARC PARISIEN, ${ }^{3}$ FRANCOIS MAJOR, ${ }^{3}$ \\ and DOUGLAS H. TURNER ${ }^{1,4}$ \\ ${ }^{1}$ Department of Chemistry, University of Rochester, Rochester, New York 14627, USA \\ ${ }^{2}$ Department of Biochemistry and Biophysics, University of Rochester School of Medicine and Dentistry, Rochester, New York 14642, USA \\ ${ }^{3}$ Department of Computer Science and Operations Research, University of Montreal, Montreal, Quebec H3C CJ7, Canada
}

\begin{abstract}
The NMR solution structure is reported of a duplex, 5'GUGAAGCCCGU/3'UCACAGGAGGC, containing a $4 \times 4$ nucleotide internal loop from an R2 retrotransposon RNA. The loop contains three sheared purine-purine pairs and reveals a structural element found in other RNAs, which we refer to as the 3RRs motif. Optical melting measurements of the thermodynamics of the duplex indicate that the internal loop is $1.6 \mathrm{kcal} / \mathrm{mol}$ more stable at $37^{\circ} \mathrm{C}$ than predicted. The results identify the $3 R R s$ motif as a common structural element that can facilitate prediction of 3D structure. Known examples include internal loops having the pairings: 5'GAA/3'AGG, 5' GAG/3'AGG, 5' GAA/3'AAG, and 5'AAG/3'AGG. The structural information is compared with predictions made with the MC-Sym program.
\end{abstract}

Keywords: retrotransposon; RNA structure; RNA motif; NMR; internal loop

\section{INTRODUCTION}

Free-energy minimization with restraints from sequence comparison (Luck et al. 1996; Hofacker et al. 2002; Mathews and Turner 2002; Havgaard et al. 2005; Reeder and Giegerich 2005), chemical mapping (Mathews et al. 2004; Deigan et al. 2009; Watts et al. 2009), NMR (Hart et al. 2008), and a combination of those methods (Kierzek et al. 2009; Mathews et al. 2010) is allowing rapid determination of RNA secondary structures. Determination of RNA three-dimensional structures, however, remains difficult (Moore 1999; Doherty and Doudna 2001). To compensate for the difficulty in determination of threedimensional structures, various methods are being devised to model them from sequence. The methods include homology modeling aided by human intuition (Martinez et al. 2008; Westhof et al. 2010), and/or knowledge-based

\footnotetext{
${ }^{4}$ Corresponding author.

E-mail turner@chem.rochester.edu.

Article published online ahead of print. Article and publication date are at http://www.rnajournal.org/cgi/doi/10.1261/rna.2641911.
}

course force fields (Malhotra and Harvey 1994; Tan et al. 2006; Das and Baker 2007; Ding et al. 2008; Parisien and Major 2008; Jonikas et al. 2009; Parisien et al. 2009; Das et al. 2010; Pasquali and Derreumaux 2010), and/or lowresolution experimental data, and/or bioinformatics data (Gherghe et al. 2009; Flores and Altman 2010; Yang et al. 2010; Seetin and Mathews 2011). There are relatively few benchmarks available, however, for testing and optimizing these methods, especially all atom methods. NMR structures of small RNA internal loops in solution (SantaLucia and Turner 1993; Wu and Turner 1996; Heus et al. 1997; Butcher et al. 1999; Schmitz et al. 1999a,b; Znosko et al. 2002; Chen et al. 2005, 2006, 2007; Shankar et al. 2006, 2007; Tolbert et al. 2007) provide benchmarks for the full range of methods. Comparisons with predictions are straightforward because the structures depend only on interactions within the RNA and between the RNA and solvent. Here, the NMR structure is reported of a $4 \times 4$ nucleotide internal loop from an R2 retrotransposon (Kierzek et al. 2009). Comparisons with previous structures (Ban et al. 2000; Carter et al. 2000; Pioletti et al. 2001; Chen et al. 2005, 2006; Kazantsev et al. 2005; Schuwirth et al. 2005; Korostelev et al. 
2006; Harms et al. 2008) reveal a common motif for three purine-purine sheared pairs.

R2 retrotransposons insert their sequence into a host genome by a target-primed reverse transcription mechanism that relies on the R2 protein (Luan et al. 1993). Such retrotransposons are common in arthropods. The internal loop studied here (Fig. 1) is found in the R2 retrotransposon RNA from Bombyx mori (Kierzek et al. 2008, 2009) and occurs in a 320-nucleotide fragment that tightly binds one copy of R2 protein (Christensen et al. 2006). The loop is near the leading edge of a 41-nucleotide RNA hairpin that has a conserved secondary structure and codes for a region of partially conserved amino acids in the R2 protein (Kierzek et al. 2009).

As shown in Figure 1, the R2 internal loop potentially contains an AG pair, but the other nucleotides are not conserved in related internal loops in four other silk moth species (Kierzek et al. 2009). Isostericity matrices (Leontis et al. 2002) do not suggest a common folding for the four known sequences. The sequence of the $B$. mori internal loop is also not found in known three-dimensional structures of RNA, and there is no three-dimensional structural information available for retrotransposons. There are many potential three-dimensional structures for the $B$. mori internal loop, however. For example, the internal loop could form three consecutive AG pairs and a bulged $C$ and A on opposite sides of the loop. Motifs with three consecutive AG pairs can be very stable (Chen and Turner 2006). Alternatively, sheared AA and AG pairs (trans Hoogsteen/ sugar edge AA or AG, abbreviated tH/S AA or AG) could

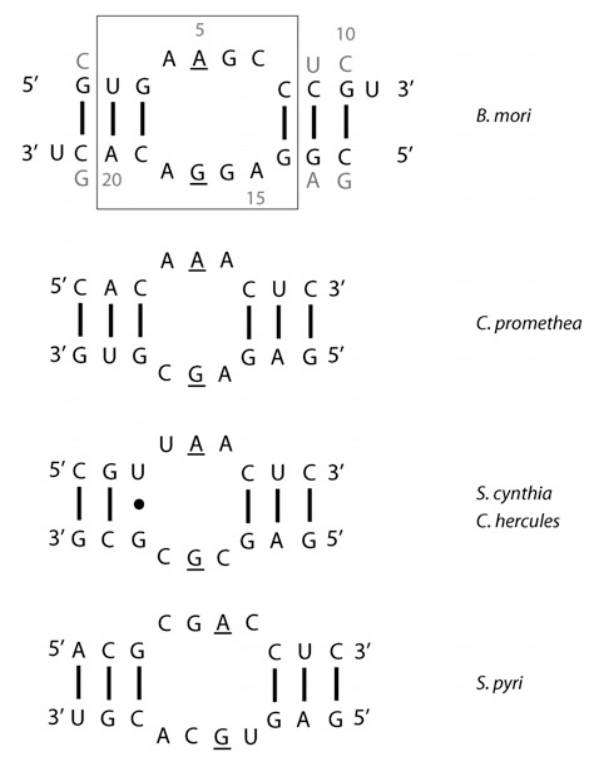

FIGURE 1. (Top) Internal loop studied in this work. Boxed region is identical to natural sequence from B. mori. Nucleotides above and below duplex are a natural sequence that was changed for this study. (Bottom) Sequences of loops in Callosamia promethea, Samia cynthia, Coscinocera hercules, and Saturnia pyri (Kierzek et al. 2009). Nucleotides potentially in an AG pair are underlined. form adjacent to an N1-carbonyl, N7-amino (trans WatsonCrick/Hoogsteen, abbreviated tWC/H) GG pair (Burkard and Turner 2000) and a cis Watson-Crick/Watson-Crick (cWC/WC) protonated CA pair (Legault and Pardi 1997). Many other possibilities exist. Thus, the structure provides a new benchmark for testing methods of predicting local three-dimensional structures. The structure is compared with predictions generated by the MC-Sym program (Parisien and Major 2008).

\section{RESULTS}

\section{Thermodynamics}

The thermodynamic stability of the duplex studied by NMR (Fig. 1) was measured by optical melting in $1 \mathrm{M}$ $\mathrm{NaCl}$ at $\mathrm{pH} 6.5$ and $\mathrm{pH} 5.0$ (Table 1). The values of $\Delta \mathrm{G}_{37}{ }^{\circ}$ from $\mathrm{T}_{\mathrm{M}}{ }^{-1}$ vs. $\log \mathrm{C}_{\mathrm{T}}$ plots are $-7.04 \pm 0.14$ and $-7.03 \pm$ $0.24 \mathrm{kcal} / \mathrm{mol}$, respectively, at $\mathrm{pH} 6.5$ and $\mathrm{pH}$ 5.0. Thus, there is no thermodynamic evidence for protonation of the duplex, which might be seen with certain CA pairs (Chen et al. 2009). Values of $\Delta \mathrm{H}^{\circ}$ from $\mathrm{T}_{\mathrm{M}}{ }^{-1}$ vs $\log \mathrm{C}_{\mathrm{T}}$ plots and from fitting melting curves differ by $4 \%$ and $19 \%$ at $\mathrm{pH} 6.5$ and $\mathrm{pH} 5.0$, respectively, consistent with two-state and not quite two-state melting, respectively.

The free-energy increment at $37^{\circ} \mathrm{C}$ attributable to the loop is $0.57 \mathrm{kcal} / \mathrm{mol}$ as calculated from Gralla and Crothers (1973):

$$
\begin{aligned}
& \Delta \mathrm{G}_{37^{\circ}}\left(5^{\prime} \mathrm{GAAGCC} / 3^{\prime} \mathrm{CAGGAG}\right)=\Delta \mathrm{G}_{37^{\circ}} \\
& \left(5^{\prime} \mathrm{GUGAAGCCCGU} / 3^{\prime} \mathrm{UCACAGGAGGC}\right)-\Delta \mathrm{G}_{37^{\circ}} \\
& \left(5^{\prime} \mathrm{GUGCCGU} / 3^{\prime} \mathrm{UCACGGC}\right)+\Delta \mathrm{G}_{37^{\circ}}\left(5^{\prime} \mathrm{GC} / 3^{\prime} \mathrm{CG}\right) .
\end{aligned}
$$

Here, the value for the duplex without an internal loop is calculated from nearest-neighbor parameters (Xia et al. 1998; Burkard et al. 1999; Turner 2000). The current model for predicting the free-energy increment for internal loops (Mathews et al. 2004) predicts $2.21 \mathrm{kcal} / \mathrm{mol}$ at $37^{\circ} \mathrm{C}$. Evidently, this internal loop is unusually stable.

\section{Exchangeable proton spectra}

Figure 2 shows 1D imino proton, 2D SNOESY, and ${ }^{1} \mathrm{H}_{-}{ }^{15} \mathrm{~N}$ HSQC spectra for the duplex at $\mathrm{pH} 6.5$ and $0^{\circ} \mathrm{C}$. The spectra confirm five of the expected six Watson-Crick base pairs and provide the assignments shown in Figure 2. The imino peaks for Watson-Crick pairs were confirmed by typical NOE connections to cytosine amino and H5 and H6 protons for GC pairs and to adenine $\mathrm{H} 2$ protons for $\mathrm{AU}$ pairs. No imino resonance is observed at $\mathrm{pH} 6.5$ for the terminal base pair formed by G10, presumably due to fast exchange with water. At pH 5.2, however, a broad resonance at $12.65 \mathrm{ppm}$ is attributed to G10 with typical NOE connections to $\mathrm{C} 12$ amino and $\mathrm{H} 5 / \mathrm{H} 6$ protons (data not shown). Pronounced resonances attributable to the non-Watson-Crick 
TABLE 1. Thermodynamic parameters for duplex formation by 5'-GUGAAGCCCGU/3'-UCACAGGAGGC

\begin{tabular}{|c|c|c|c|c|c|}
\hline & & $\begin{array}{c}\Delta \mathrm{H}^{\circ} \\
(\mathrm{kcal} / \mathrm{mol})\end{array}$ & $\begin{array}{c}\Delta \mathrm{S}^{\circ} \\
(\mathrm{cal} / \mathrm{K} \mathrm{mol})\end{array}$ & $\Delta \mathrm{G}_{37^{\circ}}(\mathrm{kcal} / \mathrm{mol})$ & $\begin{array}{l}\mathrm{Tm}^{\mathrm{a}} \\
\left({ }^{\circ} \mathrm{C}\right)\end{array}$ \\
\hline \multirow[t]{2}{*}{ Curve fit parameters } & $\mathrm{pH} 6.5$ & $-89.58 \pm 24.26$ & $-266.10 \pm 78.22$ & $-7.05 \pm 0.19$ & 38.8 \\
\hline & $\mathrm{pH} 5.0$ & $-63.19 \pm 12.93$ & $-181.27 \pm 41.99$ & $-6.97 \pm 0.35$ & 39.2 \\
\hline $1 / T_{M}$ vs $\ln \left(C_{T}\right)$ parameters ${ }^{b}$ & $\begin{array}{l}\mathrm{pH} 6.5 \\
\mathrm{pH} 5.0\end{array}$ & $\begin{array}{l}-86.19 \pm 7.13 \\
-51.03 \pm 6.03\end{array}$ & $\begin{array}{l}-255.19 \pm 23.08 \\
-141.85+19.48\end{array}$ & $-7.04 \pm 0.14$ & 38.9 \\
\hline Predicted $^{\mathrm{C}}$ & & -51.43 & -148.62 & $-5.40^{\mathrm{d}}$ & 30.0 \\
\hline
\end{tabular}

${ }^{\mathrm{a}}$ Calculated for an oligonucleotide concentration of $10^{-4} \mathrm{M}$.

bPlots of $\mathrm{T}_{\mathrm{M}}{ }^{-1}$ vs $\ln \left(\mathrm{C}_{\mathrm{T}} / 4\right)$ had an $r$ value of 0.98 at $\mathrm{pH} 6.5$ and 0.96 at $\mathrm{pH} 5$.

${ }^{\circ}$ Values for $\Delta \mathrm{H}^{\circ}, \Delta \mathrm{S}^{\circ}$, and $\Delta \mathrm{G}^{\circ}$ were predicted from nearest neighbor parameters that incorporate previously published data (Xia et al. 1998;

Burkard et al. 1999; Turner 2000; Mathews et al. 2004; Lu et al. 2006).

${ }^{\mathrm{d}}$ The free-energy change was approximated by $\Delta \mathrm{G}^{\circ}(\mathrm{T})=\Delta \mathrm{H}^{\circ}-\mathrm{T} \Delta \mathrm{S}^{\circ}$, where $\mathrm{T}$ is $310.15 \mathrm{~K}\left(37^{\circ} \mathrm{C}\right)$.

paired nucleotides G6, G16, G17, and U22 are also observed at pH 6.5 (Fig. 2). G17 is assigned by cross-peaks to A4H2 and H8. G16 is distinguished from G6 by a cross-peak to A5H8. $\mathrm{U} 22$ is identified as a uracil by the chemical shift of N3 and is assigned by cross-peaks to C21 aminos and to U22H5. No peak is identified for U11.

The different behavior of the two 3'-dangling end U's and their adjacent GC pairs is consistent with free-energy increments (Xia et al. 1998; Turner 2000), which predict that the equilibrium constants for hydrogen-bond formation and for stacking of the $3^{\prime}$-dangling end $U$ on each end will be different at $0^{\circ} \mathrm{C}$. In particular, the predicted difference in free energy at $0^{\circ} \mathrm{C}$ between formation of a terminal GC base pair and a $3^{\prime}$ unpaired $\mathrm{C}$ for $5^{\prime} \mathrm{GU} / 3^{\prime} \mathrm{CA}$ is $-3.34+0.57=-2.77 \mathrm{kcal} / \mathrm{mol}$, corresponding to an equilibrium constant of 164.6 , leaving only $0.6 \%$ unpaired G. In contrast, the predicted difference between a terminal GC base pair and a $3^{\prime}$ unpaired $G$ for $5^{\prime} \mathrm{CG} / 3^{\prime} \mathrm{GC}$ is -3.35 $+2.54=-0.81 \mathrm{kcal} / \mathrm{mol}$, corresponding to an equilibrium constant of 4.45 , leaving $18 \%$ unpaired G. Both calculations ignore stacking of a $5^{\prime}$ dangling end nucleotide, which is predicted to be negligible (Turner 2000). Different stacking of the $3^{\prime}$ dangling end U's may also contribute to a different exchange with water at the two ends. Equilibrium constants for stacking of a $3^{\prime}$ dangling end $\mathrm{U}$ on a $\mathrm{C}$ or $\mathrm{G}$ will be roughly 35 and 6 , respectively, at $0^{\circ} \mathrm{C}$ (Turner 2000), corresponding to $97 \%$ and $86 \%$ stacked on the adjacent base pair. Thus, the terminus with $\mathrm{U} 22$ is predicted to be folded more tightly than that with U11. Evidently the tighter folding protects $\mathrm{G} 1 \mathrm{H} 1$ and $\mathrm{U} 22 \mathrm{H} 3$ from exchange with water. The broad signal near $\sim 11.3 \mathrm{ppm}$ is largely from all imino protons of a single RNA strand present in slight excess over the other strand.

\section{Nonexchangeable proton spectra}

Figure 3 shows a 2D NOESY spectrum at $\mathrm{pH} 6.5$ and $20^{\circ} \mathrm{C}$. As shown in Figure 3, the backbone NOESY walk is similar to A-form RNA through both strands except near G17, where the cross-peak connecting G17H8 with G16H1' is very weak due to a weak G17H8-G16H2' cross-peak. The latter eliminates spin diffusion through $\mathrm{H} 2{ }^{\prime}$. A ${ }^{1} \mathrm{H}_{-}{ }^{13} \mathrm{C}$ HSQC spectrum at $\mathrm{pH} 5.5$ does not show a shifted adenine

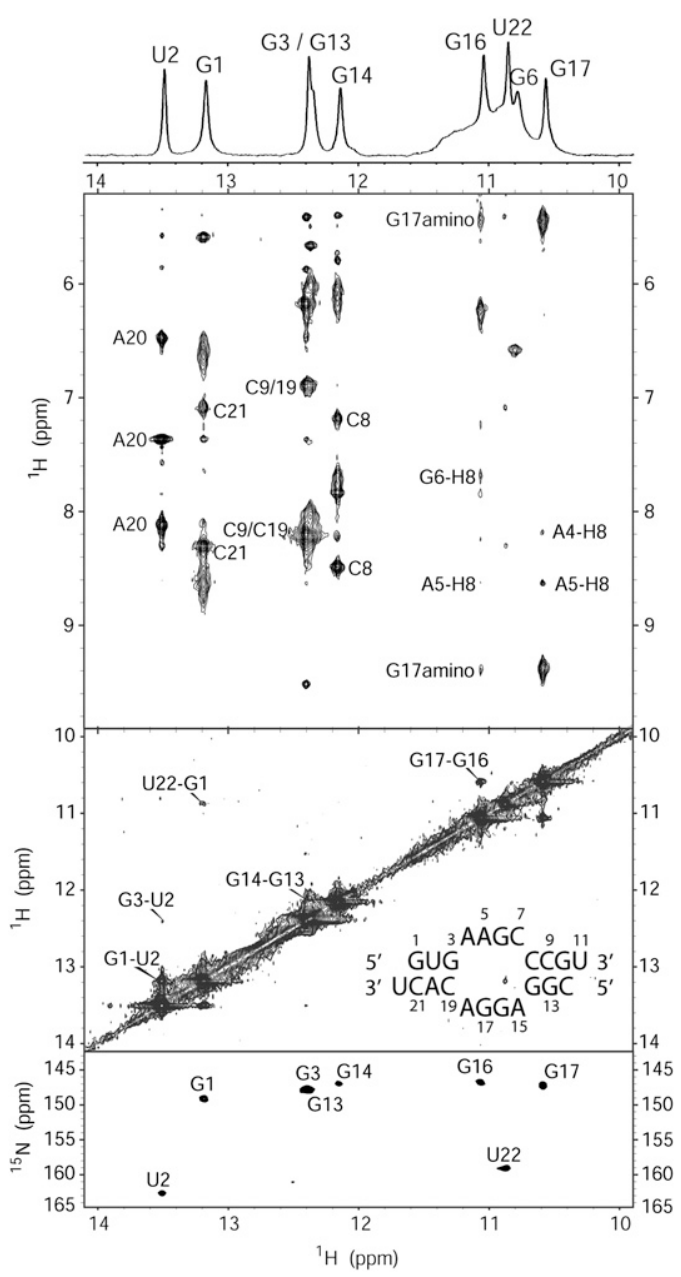

FIGURE 2. NMR spectra of the internal loop from B. mori R2 retrotransposon $5^{\prime} \mathrm{RNA}$ in 90:10 (v/v) $\mathrm{H}_{2} \mathrm{O}: \mathrm{D}_{2} \mathrm{O}$ at $0^{\circ} \mathrm{C}$ and $\mathrm{pH} 6.5$. The imino proton region is shown. At top is the $1 \mathrm{D}$ spectrum; the middle presents two regions of a $2 \mathrm{D}$ SNOESY spectrum (mixing time $=100$ $\mathrm{msec})$; at bottom is a proton-nitrogen HSQC spectrum. The 22-mer model duplex is shown in the inset. 


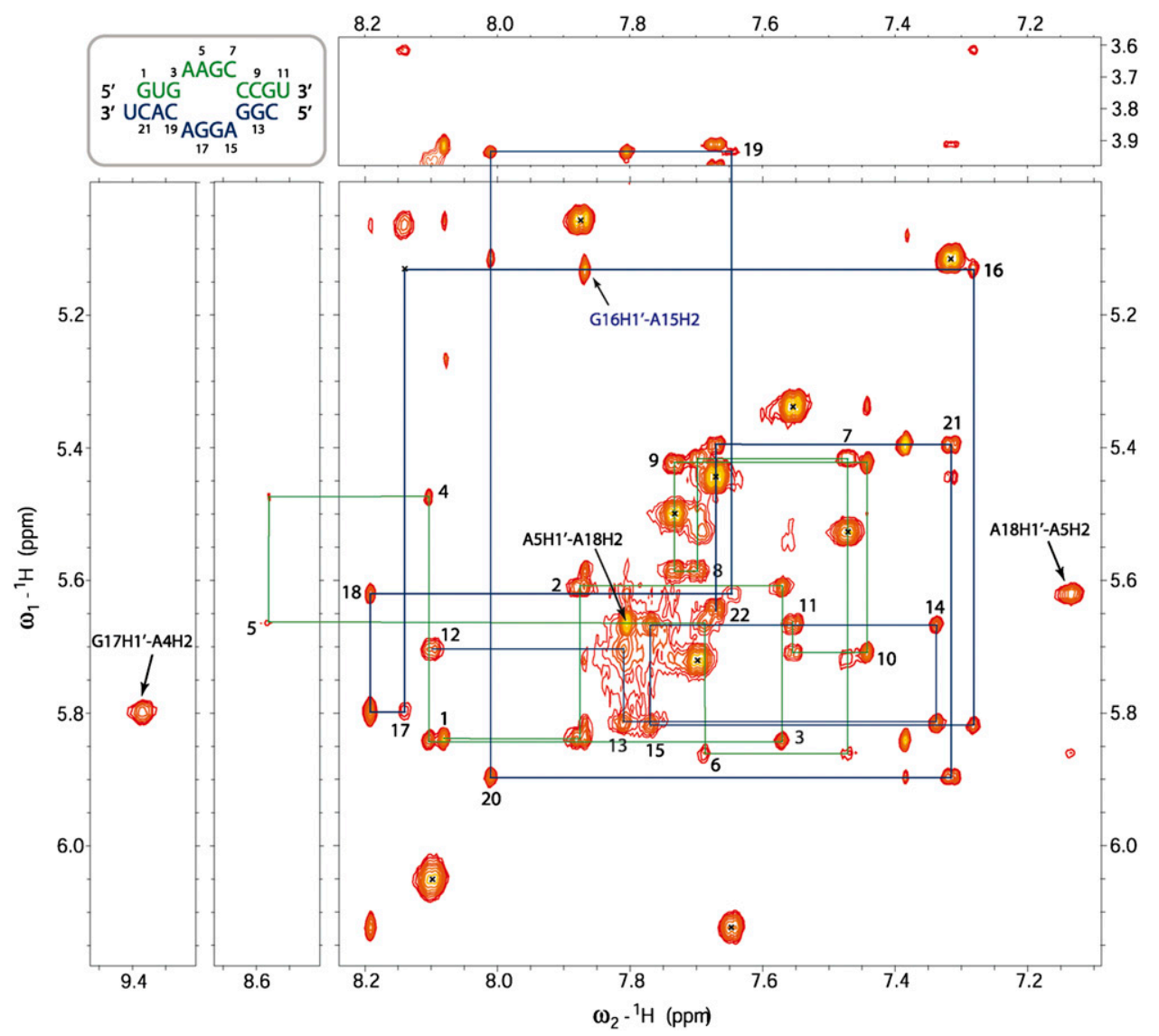

FIGURE 3. 2D NOESY spectrum of the $\mathrm{R} 2$ internal loop in $100 \% \mathrm{D}_{2} \mathrm{O}$ at $20^{\circ} \mathrm{C}$ showing the $\mathrm{H} 8 / \mathrm{H} 6 / \mathrm{H} 2 \mathrm{H} 1^{\prime} / \mathrm{H} 5$ region. The mixing time is 400 msec. $\mathrm{C}$ and U H5-H6 NOEs are indicated by crosses. Important cross-strand NOEs involving adenine H2 protons are indicated in black.

C2 resonance, which would be expected if a protonated adenine was present (Legault and Pardi 1997; Ravindranathan et al. 2000). $\mathrm{A}^{1} \mathrm{H}_{-}{ }^{31} \mathrm{P}$ HETCOR spectrum shows that the resonance for the phosphorus between G17 and A18 is shifted downfield by $\sim 3$ ppm relative to the other ${ }^{31} \mathrm{P}$ resonances. TOCSY and DQF-COSY spectra and $7 \mathrm{~Hz}$ splitting of $\mathrm{G} 17 \mathrm{H}^{\prime}$ indicate that the $\mathrm{G} 17$ ribose is primarily in the $\mathrm{C}^{\prime}$-endo conformation. The Supplemental Material includes tables of assignments and distance restraints deduced on the basis of the spectra.

\section{Structure description}

The structure was modeled on the basis of NMR restraints as described in the Materials and Methods and structure statistics are shown in Table 2. The overall structure is shown in Figure 4A and potential hydrogen-bonding patterns suggested by the model for the noncanonical pairs in the loop are shown in Figure 4B. All eight loop bases are primarily within the helix. Six bases are in a motif of three consecutive, highly stacked, sheared, or sheared-like purinepurine pairs. The remaining two bases are in a single hydrogen-bond AC pair involving the Watson-Crick faces. All glycosidic bonds are in the anti-configuration, and all ribose groups other than $\mathrm{G} 17$ have $\mathrm{C} 3{ }^{\prime}$-endo puckers. As observed in other sheared pairs, the helix becomes substantially narrower in the center of the loop. For all 40 calculated structures, the average $\mathrm{C}^{\prime}{ }^{\prime}$ to $\mathrm{C} 1^{\prime}$ distance in the stems is $10.7 \pm 0.09 \AA$, while the distance is $9.4 \pm 0.4 \AA$ at the AA pair, $9.0 \pm 0.09 \AA$ at the $\mathrm{AG}$ pair, $9.6 \pm 0.47 \AA$ at the GG pair, and $10.5 \pm 0.24 \AA$ at the $\mathrm{CA}$ pair. The noncanonical pairs are described below along with NMR evidence for them.

The A4-A18 and A5-G17 pairs each have a sheared conformation (trans Hoogsteen/Sugar edge) as illustrated in Figure 4B. Consistent with this structure are the following NMR signatures expected for a trans Hoogsteen/Sugar sheared AA or GA pair adjacent to a trans Sugar/Hoogsteen sheared purine-purine pair (SantaLucia and Turner 1993; Heus et al. 1997; Znosko et al. 2002; Chen et al. 2005, 2006): (1) the $\mathrm{C} 19 \mathrm{H} 1^{\prime}$ resonance is upfield shifted to 3.93 ppm (Fig. 5) and there is a medium NOE cross-peak between $\mathrm{C} 19 \mathrm{H}_{1}^{\prime}$ and $\mathrm{A} 18 \mathrm{H} 2$; (2) there is an $\mathrm{A} 4 \mathrm{H} 2 / \mathrm{A} 18 \mathrm{H} 8$ crosspeak, but no $\mathrm{A} 4 \mathrm{H} 8 / \mathrm{A} 18 \mathrm{H} 2$ cross-peak; (3) there are strong A4H2/G17H1', A5H2/A18H1', and A18H2/A5H1' crosspeaks corresponding to distances of $3.1,3.2$, and $2.9 \AA$, respectively, indicating a narrow minor groove, because these distances are expected to be at least 9.5, 3.7, and $3.7 \AA$, 
TABLE 2. NMR structure statistics for the duplex 5'GUGAAGCCCGU/3'UCACAGGAGGC from the R2 retrotransposon 5'RNA

\begin{tabular}{|c|c|c|c|c|c|c|c|c|}
\hline $\begin{array}{l}\text { Total NOEs/ } \\
\text { intranucleotide/ } \\
\text { internucleotide/ } \\
\text { long range }(|\mathrm{i}-\mathrm{j}| \geq 2)\end{array}$ & $\begin{array}{l}\mathrm{H} \text {-bond } \\
\text { restraints }\end{array}$ & $\begin{array}{l}\text { Backbone } \\
\text { dihedral } \\
\text { restraints }\end{array}$ & $\begin{array}{l}\text { \# of structures } \\
\text { calculated/ } \\
\text { accepted }\end{array}$ & $\begin{array}{c}\text { RMSD } \\
\text { for all heavy } \\
\text { atoms }\left(\stackrel{\AA}{ }(\AA)^{\mathrm{a}}\right)^{2}\end{array}$ & $\begin{array}{c}\text { RMSD } \\
\text { for all } \\
\text { atoms }(\stackrel{\AA}{A})^{\text {a }}\end{array}$ & $\begin{array}{c}\text { Average } \\
\text { NOE } \\
\text { RMSD(A) }\end{array}$ & $\begin{array}{c}\text { Average } \\
\text { dihedral } \\
\text { RMSD (deg) }\end{array}$ & $\begin{array}{l}\text { \# Violations } \\
>0.2 \AA / 5^{\circ} \\
\text { dist/dihedral }\end{array}$ \\
\hline $215 / 79 / 136 / 40$ & 17 & 135 & $40 / 10$ & 0.6 & 0.64 & 0.003 & 0.57 & $0 / 0$ \\
\hline
\end{tabular}

${ }^{\text {a }}$ These values represent the uniformity of the 10 structures with the lowest constraint energy, and having no distance and dihedral angle violations exceeding $0.2 \AA$ and $5^{\circ} \AA$, respectively.

respectively, for A-form RNA; (4) there is a strong cross-peak from G17H22 (amino) to A5H8. Moreover, one resonance from the G17 amino group is at $9.3 \mathrm{ppm}$, which indicates hydrogen bonding consistent with a G17-A5 sheared pair (Fig. 4B), and the downfield chemical shift of A4H2 to 9.4 ppm (Fig. 5) is expected due to the ring current effect from A18.

While the A4-A18 and A5-G17 pairs are both sheared, they differ in that the AA pair is relatively planar, whereas the AG pair has substantial twist (Fig. 4A). The orientation of the G17 base places $\mathrm{G} 16 \mathrm{H} 2$ ' directly under the aromatic rings and results in an upfield chemical shift of $\mathrm{G} 16 \mathrm{H} 2^{\prime}$, which is predicted by the program NUCHEMICS (Fig. 5; Wijmenga et al. 1997; Cromsigt et al. 2001). The twist is, at least in part, a result of the backbone distortion required to accommodate the adjacent sheared GG base pair (see below). The backbone distortion includes a C2'-endo G17 sugar pucker and G17 $\zeta$ dihedral of $\sim 180^{\circ}$ instead of the usual A-form value of $-71^{\circ}$. There is precedent for $\mathrm{C} 2^{\prime}$ endo sugar puckers for $G$ nucleotides in sheared GA pairs when they are not flanked by CG or UG wobble pairs (Heus et al. 1997; Chen et al. 2005, 2006; Tolbert et al. 2007).

The G6-G16 pair is the least well defined by the NMR spectra. A cross-peak to $\mathrm{A} 5 \mathrm{H} 8$ from $\mathrm{G} 16 \mathrm{H} 1$ indicates that G16 reaches across the helix. Medium cross-peaks from G16H1 to G17 imino and amino protons also help place G16. There is a weak G6H8/G16H1 cross-peak that is consistent with spin diffusion in the one hydrogen-bond base-base amino-N7 GG pair shown in Figure 4B. Also consistent with this pairing is the lack of NOEs to the G6 imino proton, with the exception of weak cross-peaks to $\mathrm{C} 7 \mathrm{H} 1{ }^{\prime}$ and $\mathrm{A} 5 \mathrm{H} 2$. This pairing is not definitive because an expected NOE from G16 amino protons to G6H8 and a downfield shift of a G16 amino as expected for a hydrogen bond are not observed. It is possible that the hydrogen bond is not formed and no G16 amino-G6H8 cross-peak is observed because both of these resonances are broad and the expected cross-peak is obscured by stronger, nearly overlapping cross-peaks. The pairing in Figure 4B is similar to the trans Hoogsteen/Sugar Edge classification (Leontis et al. 2002). Of the 40 calculated structures, three show a slightly different pairing in which the G16 amino forms a hydrogen bond or close electrostatic interaction with the carbonyl oxygen of G6 instead of N7. The NMR data does not distinguish between these two pairing options, and it is reasonable to expect exchange between them or other similar conformations. Such exchange could contribute to lack of NMR signatures expected for the GG structure in Figure 4B.

Another observation consistent with the modeled conformation of the G6-G16 pair is that the chemical shift of $\mathrm{G} 16 \mathrm{H} 2^{\prime}$ is unusual (3.61 ppm) and is nearly identical to that observed for the equivalent proton in $5^{\prime}$ CGAAG/3' GAGGU (3.61ppm), 5'CGAAA/3' GAGGU (3.62ppm), and 5'CGAAG/ 3'GAAGU (3.67 ppm) (Chen et al. 2005, 2006). The stacking of G16 under G17 must be very similar to the stacking of sheared pair on sheared pair seen in these other structures as this 0 .8-ppm upfield shift is critically dependent on the position of $\mathrm{G} 16 \mathrm{H} 2^{\prime}$ relative to the ring of $\mathrm{G} 17$.

The C7-A15 pair has a cis Watson-Crick/Watson-Crick conformation with one hydrogen bond (Fig. 4B). The $\mathrm{pH}$ dependence of thermodynamics, the imino proton spectra, and a ${ }^{1} \mathrm{H}-{ }^{13} \mathrm{C}$ HSQC spectrum provide no evidence of a protonated $\mathrm{C}$ or $\mathrm{A}$. The NOE spectra, however, show a
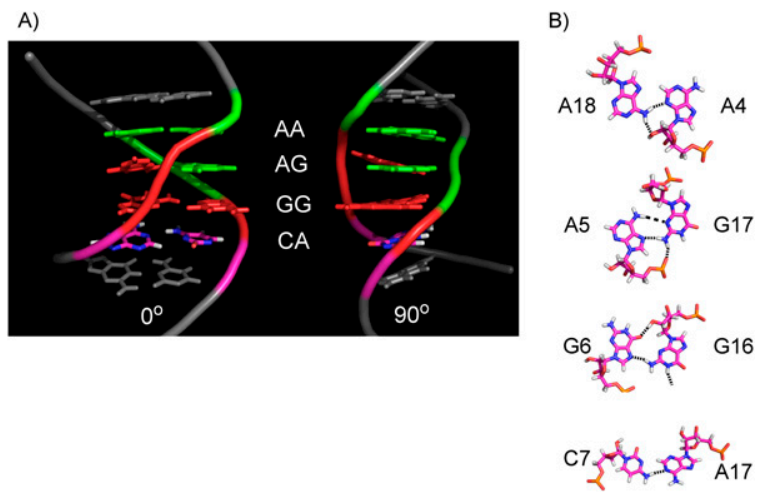

FIGURE 4. (A) Representative model of the internal loop, 5'AAGC/ 3'AGGA, from the $B$. mori R2 retrotransposon 5' RNA. Loop residues are shown in color, and closing pairs are shown in gray. The AA, AG, GG, and CA pairs can be described in the LeontisWesthof notation as $\mathrm{S} / \mathrm{H}, \mathrm{H} / \mathrm{S}, \mathrm{H} / \mathrm{S}$, and $\mathrm{W} / \mathrm{W}$, respectively. $(B)$ The structures of the four pairs of the B. mori R2 internal loop in the NMR model. The pairs are shown down the axis of the helix without rotation of the duplex about the long axis. Short dashed lines connect potential hydrogen-bond donors and acceptors that are within $2.2 \AA$ in the modeled structures. Long dashed lines connect potential hydrogen-bond donors and acceptors that are $>2.5 \AA$ apart. The dotted line from G16H1 goes to a nonbridging oxygen between A4 and A5. As discussed in the text, the G6 and G16 base pair may exchange with similar conformations. 


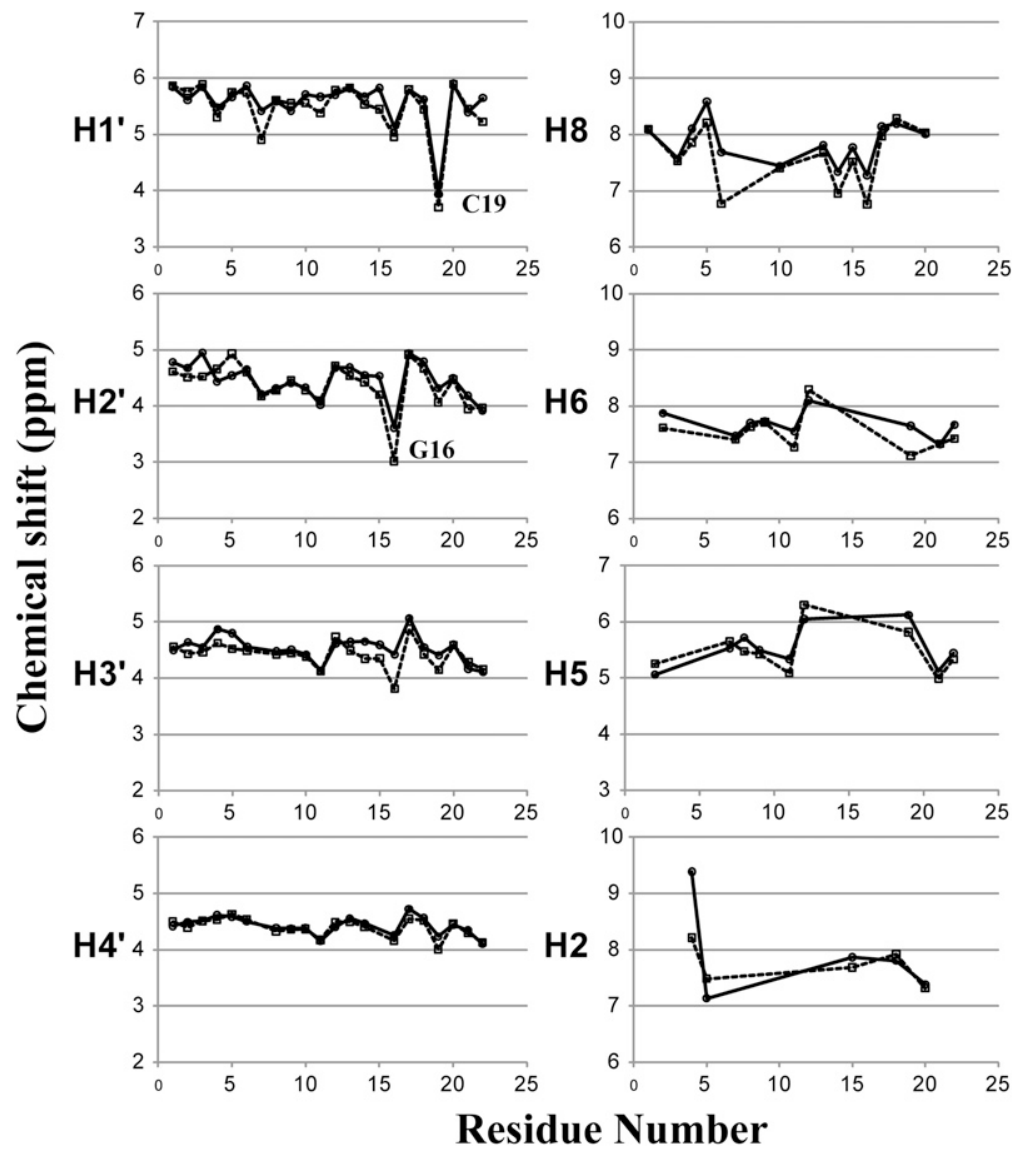

FIGURE 5. Observed (solid) and predicted (dashed) chemical shifts of each atom type plotted against residue number. Predicted shifts were calculated with the program NUCHEMICS (Wijmenga et al. 1997; Cromsigt et al. 2001) using the ensemble of 10 accepted structures.

cross-peak between $\mathrm{A} 15 \mathrm{H} 2$ and a $\mathrm{C} 7$ amino hydrogen with a chemical shift consistent with involvement in a hydrogen bond. This suggests the pairing shown in Figure 4B.

\section{Generation of alternative structures with MC-SYM}

The density of protons in RNA is limited, and force fields for RNA are less developed than those for proteins (Banas et al. 2010; Yildirim et al. 2010). Thus, it is possible that folds different from the one described above could also satisfy all the NMR restraints. The MC-Sym program (Parisien and Major 2008) was used to search for potential alternatives. The models generated by MC-Sym contained many different base-pairing types, and probabilities were assigned according to their frequencies and flanking contexts in known structures. Table 3 shows the top 10 basepairing suites for the duplex out of 88 generated. Here "suite" refers to the order and type of base pair as categorized by Leontis et al. (2002). The most probable suite is observed in 611 structures of the 10,000 generated, but only has the GG and CA pairings deduced by NMR. The suite that fits all of the pairings deduced by NMR ranks third, with a predicted probability of 0.09. On the basis of AMBER energy calculations, the pairings deduced from NMR are also not predicted to be optimal. The pairing suite deduced from NMR was identified, however, when 22 easy-to-obtain NMR restraints (NMR22) in the interior loop of the duplex were used. An easy-to-obtain subset of 79 NMR restraints (NMR-79) for the whole duplex blurs the selection, however. Finally, the full set of NMR restraints (NMR-229) reconfirms the selection of the correct base-pairing suite.

Figure 6A compares the NMR structure with the unrestrained MC-Sym structure with the correct base-pairing suite and the lowest RMSD with the NMR-solved structure $(1.24 \AA)$. This MC-Sym structure, however, does not minimize the NMR loop violations. The two MC-Sym structures that minimize the NMR loop violations when using NMR-22 have 1.52 (Fig. 6B) and $2.73 \AA$ of RMSD with the NMR-solved structure; the one that minimizes the violations using NMR-79 has $1.72 \AA$ RMSD; similarly, NMR-229 (see Supplemental Table SM1) gives $1.72 \AA$ RMSD. The MC-Sym structure with the lowest energy as evaluated by AMBER has $2.73 \AA$ of RMSD with the NMR-solved structure. Thus, the MC-Sym approach with NMR restraints confirms the NMR structure and does not find an alternative structure. Presumably, accurate MCSym modeling of structure will require less and less

TABLE 3. Base-pairing suite determined by NMR (0) and top 10 suites predicted by MC-SYM (1-10) without NMR restraints

\begin{tabular}{llllllc}
\hline Suite & AA & AG & GG & CA & Probabilities & $\begin{array}{c}\text { Number } \\
\text { of models }\end{array}$ \\
\hline 0 & tSH & tHS & tHS & cWW & & \\
1 & cWW & tSH & tHS & cWW & 0.225 & 611 \\
2 & cWW & cWW & cWW & cWW & 0.204 & 269 \\
3 & tSH & tHS & tHS & cWW & 0.090 & 438 \\
4 & tSH & tSH & tHS & cWW & 0.090 & 374 \\
5 & tSH & tHS & cWW & cWW & 0.078 & 181 \\
6 & cWW & tSW & tHS & cWW & 0.023 & 75 \\
7 & tSW & tSH & tHS & cWW & 0.021 & 100 \\
8 & tSW & tHS & tHS & cWW & 0.021 & 98 \\
9 & tSW & tHS & cWW & cWW & 0.018 & 58 \\
10 & cWW & cWW & tSH & tHS & 0.017 & 48 \\
\hline
\end{tabular}

Abbreviations are: c (cis), $\mathrm{H}$ (Hoogsteen), $\mathrm{S}$ (Sugar edge), $\mathrm{t}$ (trans), and W (Watson-Crick). See Leontis et al. (2002). 


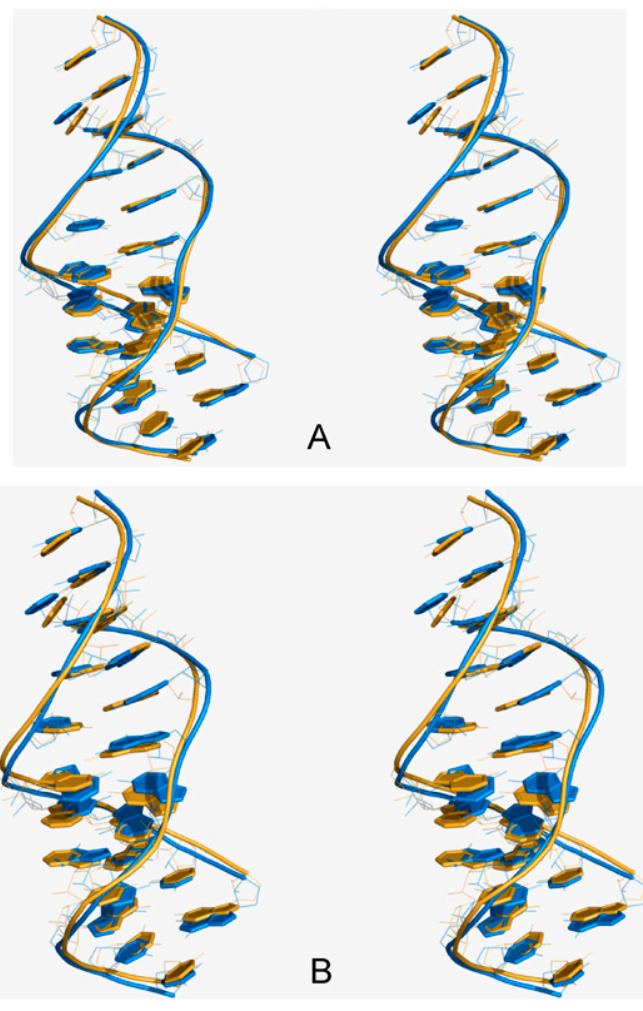

FIGURE 6. Stereoviews of two MC-Sym models (blue) superimposed with the NMR-solved structure (yellow). Cylinders thread through the phosphate atoms. (A) MC-Sym model with the best RMSD (1.24 A) to the NMR-solved structure. $(B)$ MC-Sym model with the lowest NMR loop violations (RMSD of $1.52 \AA$ ).

experimental restraints, as the database of 3D structures expands and as force fields improve.

\section{DISCUSSION}

Three-dimensional modeling of protein structures is very successful (Baker and Sali 2001; Das et al. 2007), but threedimensional modeling of RNA is not nearly as well developed. This is partly due to the much smaller database of RNA structures. The internal loop structure reported here occurs in the coding region of a retrotransposon and thus represents a structure from a class of RNA not previously studied structurally.

The internal loop contains a sheared (tSH) AA pair stacked on a sheared (tHS) AG pair. This motif of stacked, tandemsheared, purine-purine pairs is common (SantaLucia and Turner 1993; Gautheret et al. 1994; Tan et al. 2006). However, the twist of the A5G17 pair is unusual and suggests that the detailed conformation of such pairs depends on context. It may be the result of the $\mathrm{C} 2^{\prime}$-endo sugar pucker of G17 and of backbone distortions (G17 $\zeta$ dihedral $\sim 180^{\circ}$; A-form $\zeta \sim-71^{\circ}$; A18 $\beta \sim 149^{\circ}$; A-form $\beta \sim 174^{\circ}$ ) apparently required to accommodate the conformation of the following sheared (tHS) G6G16 pair. Altered sugar and backbone conformations have been seen in the $5^{\prime} \mathrm{G}$ of similar tandem sheared pairs. For instance, in cases where a tandem-sheared GA pair is flanked by a residue $5^{\prime}$ of the $\mathrm{G}$ that is in a non-Watson-Crick anti-parallel pair involving its sugar edge (placing it in the major groove), the $\mathrm{G}$ takes on the C2'-endo sugar conformation (Chen et al. 2005, 2006; Tolbert et al. 2007).

Because the C7A15 pair of this $4 \times 4$-nt loop forms an approximately Watson-Crick (cWW) pair, the structure is perhaps better described as a $3 \times 3$ loop of consecutive purine-purine sheared pairs. As shown in Figure 7, the motif reported here for $5^{\prime}$ AAG/3' AGG is strikingly similar to that formed by three tandem GA pairs, $5^{\prime} \mathrm{GAA} / 3^{\prime} \mathrm{AGG}$, in the NMR structure of an isolated internal loop (Chen et al. 2005, 2006). In each case, tandem-sheared pairs interacting with faces $\mathrm{S} / \mathrm{H}$ and $\mathrm{H} / \mathrm{S}$ are followed by another $\mathrm{H} / \mathrm{S}$ sheared pair. The backbone follows a more or less A-form path between the first two pairs, but a sharp turn required to accommodate the second H/S pair apparently causes the $\mathrm{G}$ ribose of the central AG to be $\mathrm{C} 2$ '-endo. This same structural motif is also found in at least 12 occurrences of the loop, 5'GAA/3'AGG, within crystal structures of ribosomes (Ban et al. 2000; Schuwirth et al. 2005; Korostelev et al. 2006; Harms et al. 2008; Weixlbaumer et al. 2008). Nine of these occurrences have unique closing base pairs and three form the NC stem of kink-turns (Klein et al. 2001).
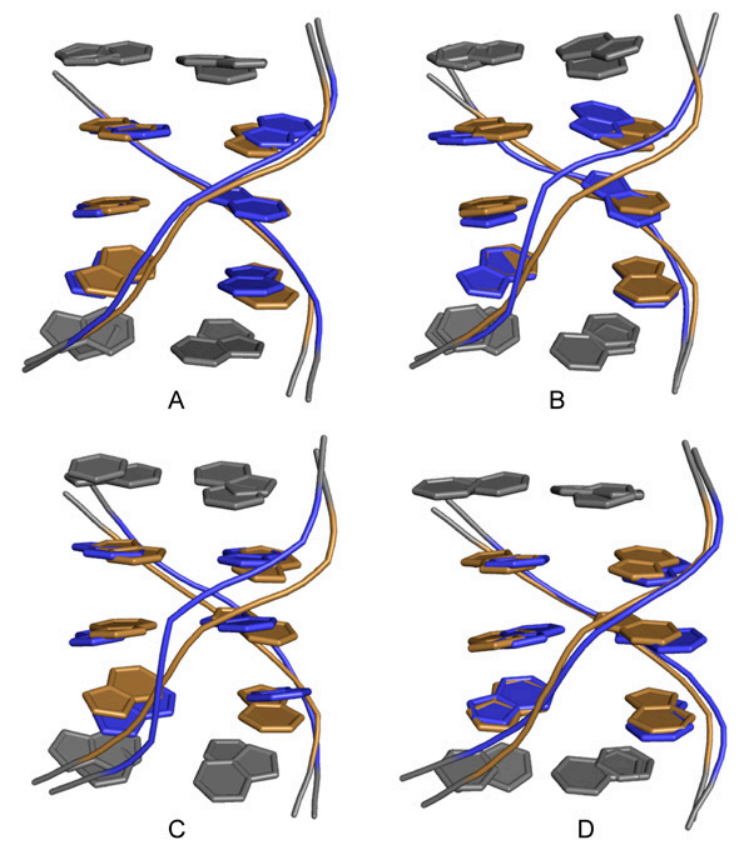

FIGURE 7. Comparison of $B$. mori R2 loop (gold) (5'GAAGCC/ 3'CAGGAG) with other loops (blue) consisting of three sheared purine-purine pairs. (A) 5'CGAAG/3' GAGGU (Chen et al. 2005), (B) 5'UGAAG/3'AAGGU (Ban et al. 2000), (C) 5'UGAGG/3'GAGGU (Schuwirth et al. 2005), and (D) 5'UGAAG/3'GAAGC (Chen et al. 2006). Closing pairs are shown in gray, including the CA pair in the $\mathrm{R} 2$ loop. Structures were aligned by pair-fitting of six $\mathrm{Cl}^{\prime}$ atoms in the loop residues. 
At least two other loops have the structural motif described above. These include both the major and minor structure observed for the internal loop, 5'GAA/3'AAG (Chen et al. 2006), and the loop, 5'UGAGG/3'GAGGU, found in the bacterial 50S subunit (Schuwirth et al. 2005). The latter is of particular interest as it contains a GG sheared pair similar to and in the same position as the GG pair in the R2 loop. Thus, the structural motif contains $3 \times 3$ nt loops comprised entirely of purine-purine sheared pairs. These include 5' GAA/3' AGG, 5' GAG/3'AGG, 5'GAA/3'AAG, and here, 5'AAG/3'AGG. We call this the 3RRs motif, where $R$ represents the purines, $A$ and $G$, and $s$ represents "sheared." The presence of this loop motif in both NMR and crystal structures indicates that it is stabilized by RNA/RNA interactions within the loop. This contrasts with the 5'CUAAG/3' GAAGC loop, where the structure in crystals of ribosomes (Harms et al. 2001; Schuwirth et al. 2005; Lee et al. 2006) is dramatically different from that in the isolated loop (Shankar et al. 2006).

Hydrogen bonds apparently contribute to the stabilities of the 3RRs motif. In the R2 NMR model, the amino group of G17 and imino hydrogen of G16 both approach a nonbridging oxygen between A4 and A5 (Fig. 8A). A similar pattern is seen in the loop with three tandem GA pairs, 5'CGAAG/3' GAGGU (Chen et al. 2005), and in 5'CGAAG/ 3'GAGGC (Kazantsev et al. 2005). Additionally, the force field generates a $2^{\prime} \mathrm{OH}$ hydrogen bond in the GG pair of the R2 RNA that is similar to one generated for the equivalent
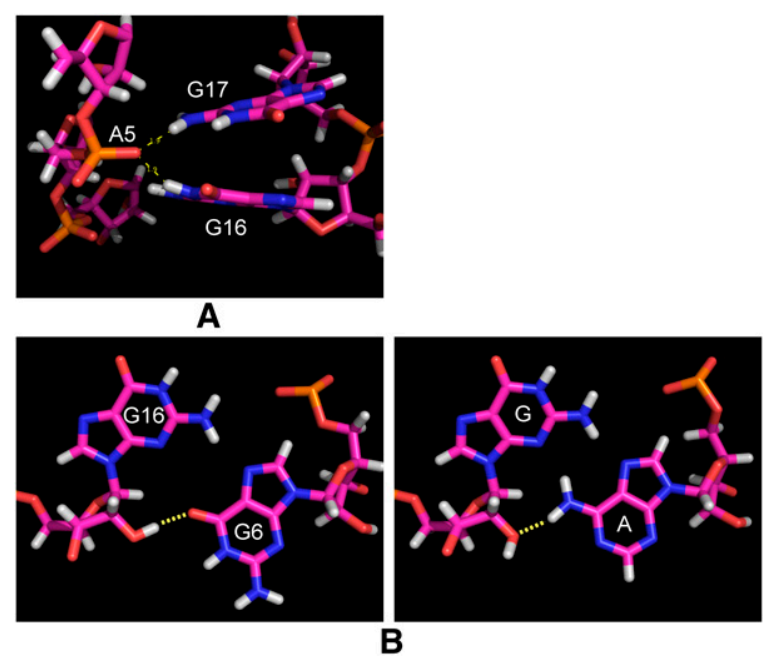

FIGURE 8. Potential hydrogen bonds or electrostatic interactions in the B. mori R2 internal loop, 5'AAG/3'AGG, and in $5^{\prime} \mathrm{GAA} / 3^{\prime} \mathrm{AGG}$. (A) G17 amino proton and G16 imino proton share negative charge of a nonbridging phosphate oxygen on A5. The same interaction is observed in $5^{\prime} \mathrm{CGAAG} / 3^{\prime} \mathrm{GAGGU}$ (Chen et al. 2005), but the distances are $\sim 1 \AA$ farther in $5^{\prime}$ CGAAG/3' GAGGC (Kazantsev et al. 2005). (B) Comparison of electrostatic interactions in the G6G16 pair of the R2 loop with the equivalent AG pair in $5^{\prime} \mathrm{CGAAG} / 3^{\prime}$ GAGGU (Chen et al. 2005). Interaction of G6 carbonyl oxygen with cross-strand 2'-OH proton (left) is replaced by interaction of $\mathrm{A}$ amino proton with crossstrand 2 '- $\mathrm{OH}$ oxygen.
AG pair in the NMR model of 5'CGAAG/3' GAGGU (Fig. $8 \mathrm{~B})$. Interaction of G6 carbonyl oxygen with the crossstrand $2^{\prime}-\mathrm{OH}$ proton in the R2 loop, 5'AAG/3'AGG, is replaced by interaction of the adenine amino proton with the cross-strand 2'-OH oxygen in 5'GAA/3'AGG. The hydrogen bond to the G6 carbonyl avoids an "unsatisfied hydrogen bond acceptor," which is expected to be energetically very unfavorable (Siegfried et al. 2010). Hydrogen bonds with $2^{\prime}-\mathrm{OH}$ groups in tertiary interactions have been shown to add $\sim 1 \mathrm{kcal} / \mathrm{mol}$ favorable free energy for folding (Sugimoto et al. 1989; Bevilacqua and Turner 1991; Pyle and Cech 1991).

The combination of three tandem GA pairs occurs often in RNA secondary structures (Kaine 1990; Klein et al. 2001; Cannone et al. 2002; Kazantsev et al. 2005; Chen and Turner 2006), including in size asymmetric internal loops. This suggests that the 3RRs motif may be very common. On the basis of secondary structure, particularly important cases may include internal loops in HIV, e.g., 5'UGGAA/ 3'GAGGGU (Daugherty et al. 2008), 5'C $\underline{\text { AGACC/ }}$ 3'GAGAAG (Damgaard et al. 2002), 5' CGAGG/3' GAAGC (Damgaard et al. 2002), and 5'CAGACC/3'GAGAGAG (Marchand et al. 2002).

The occurrence of the 3RRs structural motif depends on the closing pairs. For instance, in the loop 5'RGAAU/ $3^{\prime}$ YAAGG all three purine-purine pairs are cis WC/WC imino paired for RY = GC or AU (Carter et al. 2000; Pioletti et al. 2001), but the sequence 5'UGAAG/3' GAAGC has three sheared purine-purine pairs (Chen et al. 2006). Interestingly, seven of eight unique 3RRs loops that are closed at both ends with standard Watson-Crick pairs have pyrimidines $5^{\prime}$ of both ends of the loop. Thus, pyrimidine residues appear to be favored, but not required, on the $5^{\prime}$ edges of the 3RRs motif. The loop, 5'AAAG/3'CAGG, in the ribosomal 50S subunit is very sequence similar to the R2 loop, except that the AC pair is at the opposite end. The AG and GG pairs both form $\mathrm{H} / \mathrm{S}$ pairs as expected, but the AA pair apparently forms a parallel $\mathrm{H} / \mathrm{H}$ pair instead of an anti-parallel $\mathrm{S} / \mathrm{H}$ pair, resulting in no cross-strand stacks (Harms et al. 2008). The AC pair does not form a WC/WC pair.

The C7A15 pair in the R2 internal loop has AN1-C amino hydrogen bonding (Fig. 4B), which is unusual in that a cis Watson-Crick/Watson-Crick CA pair often has A amino to $\mathrm{CN} 3$ and protonated $\mathrm{AN} 1$ to $\mathrm{C}$ carbonyl hydrogen bonds (Butcher et al. 1999; Cheong et al. 1999; Nissen et al. 1999; Wild et al. 1999; Ban et al. 2000; Carter et al. 2000). A single A amino to $\mathrm{CN} 3$ hydrogen bond is also commonly observed in X-ray structures. While the AN1-C amino pair has been reported in NMR models (Butcher et al. 1999; Cheong et al. 1999), to our knowledge the critical NOE between the $\mathrm{C}$ amino and $\mathrm{AH} 2$ has not been reported previously. Other common hydrogen-bonding arrangements, such as $\mathrm{A}$ amino to $\mathrm{CN} 3$, require a $\mathrm{C}$ amino to $\mathrm{AH} 2$ distance that is greater than indicated by the large NOE. 
The structure of an entire 5'AGC/3'GGA triplet depends on adjacent pairs and surroundings. For example, in the crystal structure of isolated (Deng et al. 2003) or proteinbound (Batey et al. 2000, 2001) SRP RNA, the 5'AGC/ 3'GGA triplet in the internal loop, 5'AAGCAG/ 3'UGGACU, has cis WC/WC imino AG, single hydrogen bond (amino to carbonyl) S/H GG, and trans WC/H CA pairs. As isolated RNA in solution, the NMR structure of the $5^{\prime} \mathrm{AGC} / 3^{\prime} \mathrm{GGA}$ triplet retains the imino AG pair, but the CA "pair" is not hydrogen bonded (Schmitz et al. 1999a,b). The GG "pair" has a sheared-like orientation of the G's as in the NMR structure of the R2 internal loop, although the orientation is reversed and was thought not to contain base-base hydrogen bonds (Schmitz et al. 1999b). Thus, the structure of the $5^{\prime} \mathrm{AGC} / 3^{\prime} \mathrm{GGA}$ triplet in 5'AAGCAG/3'UGGACU differs from that reported here in the context of $5^{\prime}$ GAAGCC/3' 1 AGGAG (tHS AG, tHS GG, cWW CA). This difference is presumably driven by the necessity of the AG pair to be imino in the 5'AAGCAG/ $3^{\prime}$ UGGACU context to allow formation of the adjacent Watson-Crick AU pair (Gautheret et al. 1994). These structural comparisons provide interesting benchmarks for programs predicting 3D structures. For the 5'AAGCAG/ $3^{\prime}$ UGGACU internal loop, the observed suite of base pairs is the third most probable generated by MC-FOLD, but becomes the most favorable after AMBER energy minimization (data not shown).

Either G16 or G17 is conserved in the related internal loops found in four other species of silk moths (Kierzek et al. 2009), and in each case there is the possibility of forming a GA pair (Fig. 1). Moreover, the sequence of the adjacent helix on the right is more conserved than the loop (Fig. 1). It is possible that the sequence or structure of the loop and adjacent helix is important for protein binding. It would not be surprising, however, if the structure of the entire loop could be changed by protein binding. For example, the loop, 5'CUAAG/3'GAAGC, has adjacent sheared AA and GA pairs in a solution NMR structure (Shankar et al. 2006), but in ribosomes (Harms et al. 2001; Schuwirth et al. 2005) the A initially paired with the $U$ is completely bulged out of the helix. Interestingly, the 5'AAGC/3'AGGA loop studied here has the potential to bulge out an $\mathrm{A}$ and a $\mathrm{C}$ from the internal loop while forming three tandem GA pairs. The structures generated by MCSYM suggest other possible alternative folds for this sequence.

MC-SYM can generate possible 3D structures for any short RNA sequence (Parisien and Major 2008). For the duplex studied here 10,000 structures were generated, and the resulting internal loops clustered into 88 different types of base-pairing suites. On the basis of sequence alone, current knowledge of RNA energetics was not sufficient to identify the base-pairing suite determined by NMR (Table 2 ). Adding only 22 easily obtained NMR restraints, however, allowed MC-SYM to identify the experimentally deduced base-pairing. No MC-SYM structure satisfied all of the NMR restraints, however. Evidently, detailed prediction of RNA 3D structure will require expansion of the database of known structures and of knowledge of the interactions determining structure.

The structure shown in Figure 4A is $1.6 \mathrm{kcal} / \mathrm{mol}$ more stable at $37^{\circ} \mathrm{C}$ than predicted by the current thermodynamic model (Mathews et al. 2004). This corresponds to a 13-fold enhanced equilibrium constant for folding. There are eight or nine potential hydrogen bonds (acceptor-donor distance less than $\sim 2.3 \AA$ ) within the four pairs that are not accounted for in the thermodynamic model. These presumably increase the stability of the loop. The 5 'GAAGCC/ $3^{\prime}$ CAGGAG R2 loop, however, is not as stable as internal loops of three consecutive GA pairs closed by one CG pair and either a UA or UG pair. The latter free-energy increments range from -2.0 to $-2.6 \mathrm{kcal} / \mathrm{mol}$ at $37^{\circ} \mathrm{C}$ (Chen et al. 2006) in contrast to $+0.6 \mathrm{kcal} / \mathrm{mol}$ for the $\mathrm{R} 2$ loop. Comparison of the R2 structure with the structures of three consecutive GA pairs suggests a net loss of two hydrogen bonds in the R2 internal loop.

Evidently, current understanding of interactions in RNA is not sufficient to predict either thermodynamic stability or structure for small, isolated internal loops in solution. Thus, the results presented here provide a useful benchmark for testing progress in understanding RNA interactions. Better understanding of the interactions in RNA would not only allow better predictions of the most stable structures for isolated loops, but also provide insight into structures close enough in free energy to be induced by binding of proteins or other changes in environment.

\section{CONCLUSION}

The 5'GAAGCC/3'CAGGAG R2 loop is unusually stable. With the terminal CA pair forming an approximately Watson-Crick pair, the structure can be described as a $3 \times 3$ nucleotide loop. While the sequence of the B. mori R2 internal loop is not found in previously known threedimensional structures of RNA, the structure of the three purine-purine sheared pairs is similar to that found in other RNAs. Evidently, a 3RRs motif is a general building block for RNA structures, and thus far includes the following pairings: 5' $\mathrm{GAA} / 3^{\prime} \mathrm{AGG}, 5^{\prime} \mathrm{GAG} / 3^{\prime} \mathrm{AGG}, 5^{\prime} \mathrm{GAA} /$ $3^{\prime} \mathrm{AAG}$, and $5^{\prime} \mathrm{AAG} / 3^{\prime} \mathrm{AGG}$.

\section{MATERIALS AND METHODS}

\section{Sequence design}

The first base pairs closing the internal loop were made the same as found in the natural sequence (Fig. 1) because base-pair identity and orientation can affect the structure of a loop (Chen et al. 2007; Hammond et al. 2010). Additional base pairs and $3^{\prime}$ dangling end nucleotides were chosen to provide melting temperatures near $37^{\circ} \mathrm{C}$ with approximately equal stabilities for the 
two helical regions to favor two-state melting (Schroeder and Turner 2009). These additional nucleotides were also chosen to favor relatively simple NMR spectra. For example, there is only one AU pair, and all of the nearest neighbor base-pair combinations are different. No $5^{\prime} \mathrm{A}$ was included, so that the number of proton resonances was minimized.

\section{Oligonucleotide synthesis and purification}

Oligonucleotides were synthesized on an Applied Biosystems 392 DNA/RNA synthesizer, using RNA phosphoramidite chemistry (Usman et al. 1987; Wincott et al. 1995). The phosphoramidites and CPG support were bought from Glen Research or Proligo. For each $1-\mu \mathrm{mol}$ synthesis, the base-protecting groups and CPG support were removed by incubating in $2 \mathrm{~mL}$ of $3: 1(\mathrm{v} / \mathrm{v})$ ammonia/ethanol solution at $55^{\circ} \mathrm{C}$ overnight (Stawinski et al. 1988). The solid support was removed by filtration and the filtrate was lyophilized. Removal of the silyl-protecting groups on the $2^{\prime}$ hydroxyls was achieved by incubation in a 9:1 (v/v) TEA-3HF (triethylamine trihydrofluoride)/DMF mixture at $55^{\circ} \mathrm{C}$ for $2 \mathrm{~h}$ or at room temperature for $24 \mathrm{~h}$, followed by 1-butanol precipitation (Pirrung et al. 1994). The sample was lyophilized before redissolving in $5 \mathrm{mM}$ ammonium bicarbonate ( $\mathrm{pH}$ 7). The solution was loaded onto a Waters Sep-Pak C18 chromatography column to remove excess salts. The oligonucleotides were purified by TLC using a preparative Baker Si500F silica gel plate $(20 \times 20 \mathrm{~cm}, 500$ $\mu \mathrm{m}$ thick) and 55:35:10 (v/v/v) 2-propanol/ammonia/water running solution. The products were identified by UV shadowing, and the slowest-running band on the plate was scraped off. RNA was extracted from silica with RNase free water and the Sep-Pak procedure was repeated to desalt the sample. Oligonucleotide purities were checked by analytical TLC Baker Si500F silica gel plate (500- $\mu \mathrm{m}$ thick) and polyacrylamide gel electrophoresis. All samples were $>95 \%$ pure.

\section{UV melting experiments and thermodynamics}

Extinction coefficients for each single-stranded RNA were predicted from the oligonucleotide sequence using a nearest neighbor model (Borer 1975; Richards 1975), and sample concentrations were calculated from the absorbance at $260 \mathrm{~nm}$ at $80^{\circ} \mathrm{C}$. Oligonucleotides were lyophilized and dissolved in $1.0 \mathrm{M} \mathrm{NaCl}, 20 \mathrm{mM}$ sodium cacodylate, and $0.5 \mathrm{mM}$ disodium EDTA ( $\mathrm{pH} 6.5$ and $\mathrm{pH}$ 5). Absorbance versus temperature melting curves for the duplex were acquired at $260 \mathrm{~nm}$ with a heating rate of $1{ }^{\circ} \mathrm{C} / \mathrm{min}$ with a Beckman Coulter DU640C spectrophotometer with a Peltier temperature controller cooled with flowing water. Melting curves were fit to a two-state model with the Meltwin program, assuming linear sloping baselines and temperature-independent $\Delta \mathrm{H}^{\circ}$ and $\Delta \mathrm{S}^{\circ}$ (McDowell and Turner 1996). The melting temperatures, $\mathrm{T}_{\mathrm{M}}$ (in kelvin), at different concentrations were used to calculate the thermodynamic parameters according to Borer et al. (1974):

$$
\mathrm{T}_{\mathrm{M}}^{-1}=\left(\mathrm{R} / \Delta \mathrm{H}^{\circ}\right) \ln \left(\mathrm{C}_{\mathrm{T}} / 4\right)+\Delta \mathrm{S}^{\circ} / \Delta \mathrm{H}^{\circ}
$$

where $\mathrm{R}$ is the gas constant $(1.987 \mathrm{cal} / \mathrm{mol} \cdot \mathrm{K})$. The equation $\Delta \mathrm{G}^{\circ}{ }_{37}=\Delta \mathrm{H}^{\circ}-310.15 \Delta \mathrm{S}^{\circ}$ was used to calculate the free energy change at $37^{\circ} \mathrm{C}$. Thermodynamic parameters were also obtained from averaging the fits of individual melting curves.

\section{NMR sample preparation}

The two strands were mixed in $300 \mu \mathrm{L}$ of RNase free water and dialyzed for $12 \mathrm{~h}$ against $1 \mathrm{~L}$ of filtered autoclaved water in a Gibco Life Technologies microdialysis system with a 1000 molecular weight cutoff Spectro-por dialysis membrane. After dialysis, the sample was lyophilized and dissolved in $280 \mu \mathrm{L}$ of buffer ( $80 \mathrm{mM} \mathrm{NaCl}, 10 \mathrm{mM}$ sodium phosphate, $0.5 \mathrm{mM} \mathrm{Na}{ }_{2}$ EDTA at $\mathrm{pH}$ 6.5). A slightly acidic $\mathrm{pH}$ was used to decrease line broadening of exchangeable protons (Fritzsche et al. 1981). The sample was dried and reconstituted with 90:10 (v/v) $\mathrm{H}_{2} \mathrm{O} / \mathrm{D}_{2} \mathrm{O}$ for experiments involving exchangeable protons, or with $100 \% \mathrm{D}_{2} \mathrm{O}$ for spectroscopy of nonexchangeable protons. The total duplex concentration was $\sim 1.7 \mathrm{mM}$. The sample was placed in a Shigemi tube for collection of spectra.

\section{NMR spectroscopy}

Spectra were collected with Varian Inova 500 and $600 \mathrm{MHz}$ spectrometers. One-dimensional imino proton spectra of samples in 90:10 (v/v) $\mathrm{H}_{2} \mathrm{O}: \mathrm{D}_{2} \mathrm{O}$ were acquired with an $\mathrm{S}$ pulse sequence for water signal suppression (Smallcombe 1993; Lukavsky and Puglisi 2001) and a sweep width of $12 \mathrm{kHz}$ at temperatures ranging from $0^{\circ} \mathrm{C}$ to $45^{\circ} \mathrm{C}$. Assignment of exchangeable imino and amino protons was accomplished with two-dimensional SNOESY spectra recorded with mixing times of 100 and $200 \mathrm{msec}$ at temperatures of $0^{\circ} \mathrm{C}, 5^{\circ} \mathrm{C}$, and $15^{\circ} \mathrm{C}$ using a spectral width of $15,000 \mathrm{~Hz}$ in the direct dimension and either $12,000 \mathrm{~Hz}$ (no wrapped peaks) or $8176 \mathrm{~Hz}$ (imino peaks wrapped) in the indirect dimension. A natural-abundance ${ }^{1} \mathrm{H}^{15} \mathrm{~N}$ heteronuclear singlequantum coherence (HSQC) spectrum was acquired to confirm assignments of $\mathrm{G}$ and $\mathrm{U}$ imino protons.

One-dimensional spectra of the sample in $100 \% \mathrm{D}_{2} \mathrm{O}$ were acquired at temperatures ranging from $0^{\circ} \mathrm{C}$ to $70^{\circ} \mathrm{C}$. Assignment of nonexchangeable protons was accomplished with two-dimensional NOESY (mixing times of 100, 200, and $400 \mathrm{msec}$ ), DQFCOSY, TOCSY (mixing times of 13 and $80 \mathrm{msec}$ ), ${ }^{1} \mathrm{H}_{-}{ }^{13} \mathrm{C}$ HSQC, and ${ }^{1} \mathrm{H}_{-}{ }^{31} \mathrm{P}$ heteronuclear correlation (HETCOR) spectra acquired at $20^{\circ} \mathrm{C}$ with additional NOESY spectra acquired at $0^{\circ} \mathrm{C}$. DQFCOSY, TOCSY, and ${ }^{1} \mathrm{H}_{-}{ }^{13} \mathrm{C}$ HSQC spectra were all wrapped in the indirect dimension to maximize resolution.

NMRpipe software was used to process 2D spectra (Delaglio et al. 1995) and Sparky was used to assign resonances and analyze NOE cross-peak volumes (Goddard and Kneller 2004). Proton chemical shifts are reported relative to DMS by referencing to $\mathrm{H}_{2} \mathrm{O}$ or HDO (Supplemental Table S1).

\section{Generating restraints}

Internuclear distance restraints were derived from NOE (mixing time of $100 \mathrm{msec})$ cross-peak volumes using $(1 / \mathrm{r})^{6}$ scaling referenced to $\mathrm{H} 5-\mathrm{H} 6(2.45 \AA)$ and $\mathrm{H}^{\prime}-\mathrm{H} 2^{\prime}(2.75 \AA)$ peak volumes in the Watson-Crick stems. Lower and upper distance limits for nonexchangeable protons were set, allowing for a fourfold error in determination of cross-peak volumes. Restraint limits for exchangeable protons were set wider $\left( \pm 40 \%\right.$ of the $1 / \mathrm{r}^{6}$ distance determined by peak volume for slowly exchanging protons and only loose upper-limit restraints for rapidly exchanging protons). Three restraints for which no NOE was observed (3-5 lower limit and upper limit 10-15 $\AA$ for missing or very weak crosspeaks) were applied to enhance convergence in initial modeling, 
but were removed in the final modeling. Modeling without these restraints produced an average structure with an RMSD of $0.1 \AA$ relative to the average structure reported here. Watson-Crick hydrogen-bond restraints as indicated by imino proton crosspeaks in NOESY spectra were applied between bases that were not a part of the internal loop. Dihedral angle restraints were determined based on sugar proton and phosphorus scalar couplings taken from TOCSY, DQ-COSY, NOESY, and ${ }^{1} \mathrm{H}_{-}{ }^{31} \mathrm{P}$ HETCOR spectra (Varani et al. 1996). Strong $\mathrm{H} 3^{\prime}-\mathrm{H} 4^{\prime}$ peaks and the absence of $\mathrm{H}^{\prime}-\mathrm{H} 2^{\prime}$ peaks in the TOCSY spectra indicated a $\mathrm{C}^{\prime}{ }^{\prime}$-endo sugar pucker $\left(\delta \sim 81^{\circ}\right)$. $\mathrm{H} 4^{\prime}-\mathrm{H} 5^{\prime} / \mathrm{H} 5^{\prime \prime}$ J-couplings $<2 \mathrm{~Hz}$ indicated that $\gamma$ was not in the trans or $\mathrm{g}^{-}$conformation, and so the $\gamma$ dihedral angle was restrained to $\mathrm{g}^{+}\left(\gamma \sim 60^{\circ}\right)$. In cases where $\mathrm{J}\left(\mathrm{H} 4^{\prime}-\mathrm{H} 5^{\prime} / \mathrm{H}^{\prime \prime}\right)$ was $>7 \mathrm{~Hz}, \gamma$ was restrained to be trans $(\gamma$ $\left.\sim 180^{\circ}\right)$. ${ }^{31} \mathrm{P}(\mathrm{n}+1)-\mathrm{H} 3^{\prime}$ (n) J-couplings $>7 \mathrm{~Hz}$ indicated $\varepsilon \sim$ $-115^{\circ}$ (excluding $\mathrm{g}^{+}$). Weak ${ }^{31} \mathrm{P}-\mathrm{H} 5^{\prime} / \mathrm{H} 5^{\prime \prime}$ cross-peaks in ${ }^{1} \mathrm{H}^{31} \mathrm{P}$ HETCOR spectra (J-coupling $<3 \mathrm{~Hz}$ ) indicated $\beta$ in the trans conformation $\left(\sim 165^{\circ}\right)$. Measureable couplings in the stem residues were within typical A-form ranges. Consequently, backbone dihedrals in the stem were loosely restrained to A-form values: $\alpha$ $\left(-65 \pm 90^{\circ}\right), \beta\left(165 \pm 75^{\circ}\right), \gamma\left(60 \pm 60^{\circ}\right), \varepsilon\left(-115 \pm 125^{\circ}\right)$, $\zeta\left(-70 \pm 90^{\circ}\right)$ as defined previously (Richardson et al. 2008). In loop residues, all angles were restrained to A-form values, except between $\mathrm{G} 16 \varepsilon$ and $\mathrm{A} 18 \alpha$.

\section{Structure determination}

Simulated annealing was carried out with distance and dihedral angle restraints generated from NMR data. Initial structures were obtained with the program CNS version 1.2 (Brunger et al. 1998) with the following protocol: (1) high-temperature dynamics at $5000 \mathrm{~K}$ in torsion angle space for 4 psec with NOE and dihedral scale factors of $150 \mathrm{kcal} / \mathrm{mol} \AA^{2}$ and $25 \mathrm{kcal} / \mathrm{mol} \mathrm{rad}^{2}$, respectively; (2) simulated annealing in torsion angle space for 40 psec with slow cooling from 2000 to $0 \mathrm{~K}$ (40,000 steps) with NOE and dihedral scale factors of $75 \mathrm{kcal} / \mathrm{mol} \AA^{2}$ and $100 \mathrm{kcal} /$ mol $\mathrm{rad}^{2}$, respectively; (3) simulated annealing for $40 \mathrm{psec}$ in Cartesian space with slow cooling from 1000 to $0 \mathrm{~K}(40,000$ steps) with the NOE and dihedral angle scale factors constant at $75 \mathrm{kcal} / \mathrm{mol} \AA^{2}$ and $100 \mathrm{kcal} / \mathrm{mol} \mathrm{rad}^{2}$, respectively; the van der Waals factor was linearly increased from 1 to 4; and (4) Powell energy minimization was applied with full van der Waals and electrostatic terms. A total of 40 structures were calculated from randomized initial atom velocities applied to approximately A-form initial coordinates. These structures were subjected to an additional 100 psec of simulated annealing and restrained molecular dynamics using the program AMBER (version 10, ff99 force field, generalized-Born implicit solvent) (Case et al. 2008). In this annealing, the models were heated to only $600 \mathrm{~K}$ for $5 \mathrm{psec}$ with tight temperature coupling, followed by gradual cooling to $0 \mathrm{~K}$ over the next 95 psec. Distance and dihedral restraints used in the CNS calculation were also used in the AMBER calculation with scale factors of $30 \mathrm{kcal} / \mathrm{mol} \AA^{2}$ and $20 \mathrm{kcal} / \mathrm{mol} \mathrm{rad}^{2}$, respectively. Structures with distance or dihedral angle restraints exceeding 0.2 $\AA$ or $5^{\circ}$, respectively, were eliminated. Of the remaining structures, the 10 with the lowest constraint energy were selected for further analysis, and the ensemble of atomic coordinates are deposited in the Protein Data Bank with ID 2L8F. Structure analysis and figures were generated with Pymol (DeLano 2002; http://pymol.org).

\section{Structure prediction and annotation}

The MC-Sym computer program was used to generate a decoy of 10,000 3D models of the RNA duplex (Parisien and Major 2008). The four noncanonical base pairs in the duplex are spanned by three consecutive $2 \times 2$ nucleotide cyclic motifs (NCMs) (i.e., tandems of base pairs). MC-Sym systematically assigned and merged the three NCMs corresponding to the sequence of the RNA duplex. The NCMs were taken from structures available in the Protein Data Bank (PDB) (Berman et al. 2000), as well as from a library of computationally built NCMs. The latter resulted from substituting and aligning the $\mathrm{C}^{\prime}{ }^{\prime}, \mathrm{N} 1$, or $\mathrm{N} 9$, and $\mathrm{C} 2$ or $\mathrm{C} 4$ atoms of base templates with that of all $2 \times 2$ NCMs found in the PDB. The RNA duplex models were submitted to a steepest descent minimization using AMBER as implemented in the Tinker molecular modeling package version 5.0 (Ren and Ponder 2003), until a gradient RMS of $5.0 \mathrm{kcal} / \mathrm{mol} / \mathrm{A}$. $\mathrm{Na}^{+}$atoms were placed geometrically at each backbone $\mathrm{O}=\mathrm{P}-\mathrm{O}^{-}$group before minimization to counteract the negatively charged RNA backbone. During minimization, all nucleobase atoms were forced to stay at their initial location using a spring constant of $1001 \mathrm{kcal} /$ $\mathrm{mol} / \mathrm{A}^{2}$. Then, the models were submitted to the "anneal" mode of Tinker for unconstrained simulated annealing via molecular dynamics from 100 to $0 \mathrm{~K}$ for a total of $10 \mathrm{psec}$. The GB/SA model (Hasel et al. 1988) was turned on to take into account the contribution of the solvent. The RNAview program (Yang et al. 2003) was used for base-pairing type annotation and MCAnnotate (Gendron et al. 2001) was used for base stacking.

\section{SUPPLEMENTAL MATERIAL}

Supplemental material (chemical shifts, NOE-derived distance restraints, and the MC-Sym input script) is available for this article.

\section{ACKNOWLEDGMENTS}

We thank Walter Moss for creating Figure 1. This work was supported by NIH Grant GM22939 (to D.H.T.).

Received January 24, 2011; accepted May 8, 2011.

\section{REFERENCES}

Baker D, Sali A. 2001. Protein structure prediction and structural genomics. Science 294: 93-96.

Ban N, Nissen P, Hansen J, Moore PB, Steitz TA. 2000. The complete atomic structure of the large ribosomal subunit at $2.4 \AA$ resolution. Science 289: 905-920.

Banas P, Hollas D, Zgarbova M, Jurecka P, Orozco M, Cheatham TE, Sponer J, Otyepka M. 2010. Performance of molecular mechanics force fields for RNA simulations: Stability of UUCG and GNRA hairpins. J Chem Theory Comput 6: 3836-3849.

Batey RT, Rambo RP, Lucast L, Rha B, Doudna JA. 2000. Crystal structure of the ribonucleoprotein core of the signal recognition particle. Science 287: 1232-1239.

Batey RT, Sagar MB, Doudna JA. 2001. Structural and energetic analysis of RNA recognition by a universally conserved protein from the signal recognition particle. J Mol Biol 307: 229-246.

Berman HM, Westbrook J, Feng Z, Gilliland G, Bhat TN, Weissig H, Shindyalov IN, Bourne PE. 2000. The Protein Data Bank. Nucleic Acids Res 28: 235-242. 
Bevilacqua PC, Turner DH. 1991. Comparison of binding of mixed ribose-deoxyribose analogues of CUCU to a ribozyme and to GGAGAA by equilibrium dialysis: evidence for ribozyme specific interactions with 2' OH groups. Biochemistry 30: 10632-10640.

Borer PN. 1975. Optical properties of nucleic acids, absorption and circular dichroism spectra. In Handbook of biochemistry and molecular biology: Nucleic acids, 3rd ed. (ed. GD Fasman), pp. 589-595. CRC Press, Cleveland, OH.

Borer PN, Dengler B, Tinoco I Jr, Uhlenbeck OC. 1974. Stability of ribonucleic acid double-stranded helices. J Mol Biol 86: 843-853.

Brunger AT, Adams PD, Clore GM, DeLano WL, Gros P, GrosseKunstleve RW, Jiang JS, Kuszewski J, Nilges M, Pannu NS, et al. 1998. Crystallography \& NMR system: A new software suite for macromolecular structure determination. Acta Crystallogr D Biol Crystallogr 54: 905-921.

Burkard ME, Turner DH. 2000. NMR structures of r(GCAGGCGUGC) and determinants of stability for single guanosine-guanosine base pairs. Biochemistry 39: 11748-11762.

Burkard ME, Kierzek R, Turner DH. 1999. Thermodynamics of unpaired terminal nucleotides on short RNA helixes correlates with stacking at helix termini in larger RNAs. J Mol Biol 290: 967-982.

Butcher SE, Allain FH, Feigon J. 1999. Solution structure of the loop B domain from the hairpin ribozyme. Nat Struct Biol 6: 212-216.

Cannone JJ, Subramanian S, Schnare MN, Collett JR, D'Souza LM, Du Y, Feng B, Lin N, Madabusi LV, Muller KM, et al. 2002. The comparative RNA web (CRW) site: an online database of comparative sequence and structure information for ribosomal, intron, and other RNAs. BMC Bioinformatics 3: 2. doi: 10.1186/ 1471-2105-3-2.

Carter AP, Clemons WM, Brodersen DE, Morgan-Warren RJ, Wimberly BT, Ramakrishnan V. 2000. Functional insights from the structure of the $30 \mathrm{~S}$ ribosomal subunit and its interactions with antibiotics. Nature 407: 340-348.

Case DA, Darden TA, Cheatham TE, Simmerling CL, Wang J, Duke RE, Luo R, Merz KM, Pearlman DA, Crowley M, et al. 2008. AMBER 10. University of California, San Francisco, CA.

Chen G, Turner DH. 2006. Consecutive GA pairs stabilize mediumsize RNA internal loops. Biochemistry 45: 4025-4043.

Chen G, Znosko BM, Kennedy SD, Krugh TR, Turner DH. 2005. Solution structure of an RNA internal loop with three consecutive sheared GA pairs. Biochemistry 44: 2845-2856.

Chen G, Kennedy SD, Qiao J, Krugh TR, Turner DH. 2006. An alternating sheared AA pair and elements of stability for a single sheared purine-purine pair flanked by sheared GA pairs in RNA. Biochemistry 45: 6889-6903.

Chen G, Kierzek R, Yildirim I, Krugh TR, Turner DH, Kennedy SD. 2007. Stacking effects on local structure in RNA: changes in the structure of tandem GA pairs when flanking GC pairs are replaced by isoG-isoC pairs. J Phys Chem B 111: 6718-6727.

Chen G, Kennedy SD, Turner DH. 2009. A CA(+) pair adjacent to a sheared GA or AA pair stabilizes size-symmetric RNA internal loops. Biochemistry 48: 5738-5752.

Cheong HK, Cheong C, Lee YS, Seong BL, Choi BS. 1999. Structure of influenza virus panhandle RNA studied by NMR spectroscopy and molecular modeling. Nucleic Acids Res 27: 1392-1397.

Christensen SM, Ye J, Eickbush TH. 2006. RNA from the 5' end of the R2 retrotransposon controls R2 protein binding to and cleavage of its DNA target site. Proc Natl Acad Sci 103: 17602-17607.

Cromsigt JA, Hilbers CW, Wijmenga SS. 2001. Prediction of proton chemical shifts in RNA. Their use in structure refinement and validation. J Biolmol NMR 21: 11-29.

Damgaard CK, Tange TO, Kjems J. 2002. hnRNP Al controls HIV-1 mRNA splicing through cooperative binding to intron and exon splicing silencers in the context of a conserved secondary structure. RNA 8: 1401-1415.

Das R, Baker D. 2007. Automated de novo prediction of native-like RNA tertiary structures. Proc Natl Acad Sci 104: 14664-14669.

Das R, Qian B, Raman S, Vernon R, Thompson J, Bradley P, Khare S, Tyka MD, Bhat D, Chivian D, et al. 2007. Structure prediction for
CASP7 targets using extensive all-atom refinement with Rosetta@ home. Proteins (Suppl 8) 69: 118-128.

Das R, Karanicolas J, Baker D. 2010. Atomic accuracy in predicting and designing noncanonical RNA structure. Nat Methods 7: 291294.

Daugherty MD, D'Orso I, Frankel AD. 2008. A solution to limited genomic capacity: using adaptable binding surfaces to assemble the functional HIV Rev oligomer on RNA. Mol Cell 31: 824-834.

Deigan KE, Li TW, Mathews DH, Weeks KM. 2009. Accurate SHAPEdirected RNA structure determination. Proc Natl Acad Sci 106: 97-102.

Delaglio F, Grzesiek S, Vuister GW, Zhu G, Pfeifer J, Bax A. 1995. Nmrpipe - a multidimensional spectral processing system based on Unix Pipes. J Biol NMR 6: 277-293.

DeLano WL. 2002. The PyMol Molecular Graphics System. DeLano Scientific, LLC, San Francisco, CA.

Deng J, Xiong Y, Pan B, Sundaralingam M. 2003. Structure of an RNA dodecamer containing a fragment from SRP domain IV of Escherichia coli. Acta Crystallogr D Biol Crystallogr 59: 10041011.

Ding F, Sharma S, Chalasani P, Demidov VV, Broude NE, Dokholyan NV. 2008. Ab initio RNA folding by discrete molecular dynamics: From structure prediction to folding mechanisms. RNA 14: 11641173.

Doherty EA, Doudna JA. 2001. Ribozyme structures and mechanisms. Annu Rev Biophys Biomol Struct 30: 457-475.

Flores SC, Altman RB. 2010. Turning limited experimental information into 3D models of RNA. RNA 16: 1769-1778.

Fritzsche H, Kan LS, Tso POP. 1981. Proton nuclear magneticresonance study on uridine imido proton-exchange. Biochemistry 20: $6118-6122$.

Gautheret D, Konings D, Gutell RR. 1994. A major family of motifs involving G.A mismatches in ribosomal RNA. J Mol Biol 242: 1-8.

Gendron P, Lemieux S, Major F. 2001. Quantitative analysis of nucleic acid three-dimensional structures. J Mol Biol 308: 919-936.

Gherghe CM, Leonard CW, Ding F, Dokholyan NV, Weeks KM. 2009. Native-like RNA tertiary structures using a sequence-encoded cleavage agent and refinement by discrete molecular dynamics. $J$ Am Chem Soc 131: 2541-2546.

Goddard TD, Kneller DG. 2004. SPARKY 3: NMR assignment and integration software University of California, San Francisco, CA.

Gralla J, Crothers DM. 1973. Free energy of imperfect nucleic acid helices. 3. Small internal loops resulting from mismatches. J Mol Biol 78: 301-319.

Hammond NB, Tolbert BS, Kierzek R, Turner DH, Kennedy SD. 2010. RNA internal loops with tandem AG pairs: the structure of the $5^{\prime}$ GAGU/3'UGAG loop can be dramatically different from others, including 5'AAGU/3'UGAA. Biochemistry 49: 5817-5827.

Harms J, Schluenzen F, Zarivach R, Bashan A, Gat S, Agmon I, Bartels H, Franceschi F, Yonath A. 2001. High resolution structure of the large ribosomal subunit from a mesophilic eubacterium. Cell 107: 679-688.

Harms JM, Wilson DN, Schluenzen F, Connell SR, Stachelhaus T, Zaborowska Z, Spahn CM, Fucini P. 2008. Translational regulation via L11: molecular switches on the ribosome turned on and off by thiostrepton and micrococcin. Mol Cell 30: 26-38.

Hart JM, Kennedy SD, Mathews DH, Turner DH. 2008. NMR-assisted prediction of RNA secondary structure: identification of a probable pseudoknot in the coding region of an R2 retrotransposon. $J$ Am Chem Soc 130: 10233-10239.

Hasel W, Hendrickson TF, Still WC. 1988. A rapid approximation to the solvent-accessible surface area of atoms. Tetrahedron Comput Meth 1: 103-116.

Havgaard JH, Lyngso RB, Stormo GD, Gorodkin J. 2005. Pairwise local structural alignment of RNA sequences with sequence similarity less than 40\%. Bioinformatics 21: 1815-1824.

Heus HA, Wijmenga SS, Hoppe H, Hilbers CW. 1997. The detailed structure of tandem G.A mismatched base-pair motifs in RNA duplexes is context dependent. J Mol Biol 271: 147-158. 
Hofacker IL, Fekete M, Stadler PF. 2002. Secondary structure prediction for aligned RNA sequences. J Mol Biol 319: 1059-1066.

Jonikas MA, Radmer RJ, Laederach A, Das R, Pearlman S, Herschlag D, Altman RB. 2009. Coarse-grained modeling of large RNA molecules with knowledge-based potentials and structural filters. RNA 15: 189-199.

Kaine BP. 1990. Structure of the archaebacterial 7S RNA molecule. Mol Gen Genet 221: 315-321.

Kazantsev AV, Krivenko AA, Harrington DJ, Holbrook SR, Adams PD, Pace NR. 2005. Crystal structure of a bacterial ribonuclease $\mathrm{P}$ RNA. Proc Natl Acad Sci 102: 13392-13397.

Kierzek E, Kierzek R, Moss WN, Christensen SM, Eickbush TH, Turner DH. 2008. Isoenergetic penta- and hexanucleotide microarray probing and chemical mapping provide a secondary structure model for an RNA element orchestrating R2 retrotransposon protein function. Nucleic Acids Res 36: 1770-1782.

Kierzek E, Christensen SM, Eickbush TH, Kierzek R, Turner DH, Moss WN. 2009. Secondary structures for $5^{\prime}$ regions of R2 retrotransposon RNAs reveal a novel conserved pseudoknot and regions that evolve under different constraints. J Mol Biol 390: $428-442$.

Klein DJ, Schmeing TM, Moore PB, Steitz TA. 2001. The kink-turn: a new RNA secondary structure motif. EMBO J 20: 4214-4221.

Korostelev A, Trakhanov S, Laurberg M, Noller HF. 2006. Crystal structure of a $70 \mathrm{~S}$ ribosome-tRNA complex reveals functional interactions and rearrangements. Cell 126: 1065-1077.

Lee JC, Gutell RR, Russell R. 2006. The UAA/GAN internal loop motif: a new RNA structural element that forms a cross-strand AAA stack and long-range tertiary interactions. J Mol Biol 360: 978-988.

Legault P, Pardi A. 1997. Unusual dynamics and $\mathrm{pK}_{\mathrm{a}}$ shift at the active site of a lead-dependent ribozyme. J Am Chem Soc 119: 6621-6628.

Leontis NB, Stombaugh J, Westhof E. 2002. The non-Watson-Crick base pairs and their associated isostericity matrices. Nucleic Acids Res 30: 3497-3531.

Lu ZJ, Turner DH, Mathews DH. 2006. A set of nearest neighbor parameters for predicting the enthalpy change of RNA secondary structure formation. Nucleic Acids Res 34: 4912-4924.

Luan DD, Korman MH, Jakubczak JL, Eickbush TH. 1993. Reverse transcription of R2Bm RNA is primed by a nick at the chromosomal target site: a mechanism for non-LTR retrotransposition. Cell 72: 595-605.

Luck R, Steger G, Riesner D. 1996. Thermodynamic prediction of conserved secondary structure: application to the RRE element of HIV, the tRNA-like element of CMV and the mRNA of prion protein. J Mol Biol 258: 813-826.

Lukavsky PJ, Puglisi JD. 2001. RNAPack: An integrated NMR approach to RNA structure determination. Methods 25: 316-332.

Malhotra A, Harvey SC. 1994. A quantitative model of the Escherichia coli 16 S RNA in the 30 S ribosomal subunit. J Mol Biol 240: 308-340.

Marchand V, Mereau A, Jacquenet S, Thomas D, Mougin A, Gattoni R, Stevenin J, Branlant C. 2002. A Janus splicing regulatory element modulates HIV-1 tat and rev mRNA production by coordination of hnRNP A1 cooperative binding. J Mol Biol 323: 629-652.

Martinez HM, Maizel JV Jr, Shapiro BA. 2008. RNA2D3D: a program for generating, viewing, and comparing 3-dimensional models of RNA. J Biomol Struct Dyn 25: 669-683.

Mathews DH, Turner DH. 2002. Dynalign: an algorithm for finding the secondary structure common to two RNA sequences. $J \mathrm{Mol}$ Biol 317: 191-203.

Mathews DH, Disney MD, Childs JL, Schroeder SJ, Zuker M, Turner DH. 2004. Incorporating chemical modification constraints into a dynamic programming algorithm for prediction of RNA secondary structure. Proc Natl Acad Sci 101: 7287-7292.

Mathews DH, Moss WN, Turner DH. 2010. Folding and finding RNA secondary structure. Cold Spring Harb Perspect Biol doi: 10.1101/ cshperspect.a003665.
McDowell JA, Turner DH. 1996. Investigation of the structural basis for thermodynamic stabilities of tandem GU mismatches: solution structure of (rGAGGUCUC) ${ }_{2}$ by two-dimensional NMR and simulated annealing. Biochemistry 35: 14077-14089.

Moore PB. 1999. Structural motifs in RNA. Annu Rev Biochem 68: 287-300.

Nissen P, Thirup S, Kjeldgaard M, Nyborg J. 1999. The crystal structure of Cys-tRNACys-EF-Tu-GDPNP reveals general and specific features in the ternary complex and in tRNA. Structure 7: 143-156.

Parisien M, Major F. 2008. The MC-Fold and MC-Sym pipeline infers RNA structure from sequence data. Nature 452: 51-55.

Parisien M, Cruz JA, Westhof E, Major F. 2009. New metrics for comparing and assessing discrepancies between RNA 3D structures and models. RNA 15: 1875-1885.

Pasquali S, Derreumaux P. 2010. HiRE-RNA: a high resolution coarse-grained energy model for RNA. J Phys Chem B 114: 11957-11966.

Pioletti M, Schlunzen F, Harms J, Zarivach R, Gluhmann M, Avila H, Bashan A, Bartels H, Auerbach T, Jacobi C, et al. 2001. Crystal structures of complexes of the small ribosomal subunit with tetracycline, edeine and IF3. EMBO J 20: 1829-1839.

Pirrung MC, Shuey SW, Lever DC, Fallon L. 1994. A convenient procedure for the deprotection of silylated nucleosides and nucleotides using triethylamine trihydrofluoride. Bioorg Med Chem Lett 4: 1345-1346.

Pyle AM, Cech TR. 1991. Ribozyme recognition of RNA by tertiary interactions with specific ribose 2'-OH groups. Nature 350: 628-631.

Ravindranathan S, Butcher SE, Feigon J. 2000. Adenine protonation in domain B of the hairpin ribozyme. Biochemistry 39: 16026-16032.

Reeder J, Giegerich R. 2005. Consensus shapes: an alternative to the Sankoff algorithm for RNA consensus structure prediction. Bioinformatics 21: 3516-3523.

Ren PY, Ponder JW. 2003. Polarizable atomic multipole water model for molecular mechanics simulation. J Phys Chem B 107: 59335947.

Richards EG. 1975. Use of tables in calculation of absorption, optical rotatory dispersion and circular dichroism of polyribonucleotides. In Handbook of biochemistry and molecular biology: Nucleic acids, 3rd ed. (ed. GD Fasman), pp. 596-603. CRC Press, Cleveland, $\mathrm{OH}$.

Richardson JS, Schneider B, Murray LW, Kapral GJ, Immormino RM, Headd JJ, Richardson DC, Ham D, Hershkovits E, Williams LD, et al. 2008. RNA backbone: consensus all-angle conformers and modular string nomenclature (an RNA Ontology Consortium contribution). RNA 14: 465-481.

SantaLucia J Jr, Turner DH. 1993. Structure of (rGGCGAGCC) $)_{2}$ in solution from NMR and restrained molecular dynamics. Biochemistry 32: 12612-12623.

Schmitz U, Behrens S, Freymann DM, Keenan RJ, Lukavsky P, Walter P, James TL. 1999a. Structure of the phylogenetically most conserved domain of SRP RNA. RNA 5: 1419-1429.

Schmitz U, James TL, Lukavsky P, Walter P. 1999b. Structure of the most conserved internal loop in SRP RNA. Nat Struct Biol 6: 634638.

Schroeder SJ, Turner DH. 2009. Optical melting measurements of nucleic acid thermodynamics. Methods Enzymol 468: 371-387.

Schuwirth BS, Borovinskaya MA, Hau CW, Zhang W, Vila-Sanjurjo A, Holton JM, Cate JH. 2005. Structures of the bacterial ribosome at 3.5 A resolution. Science 310: $827-834$.

Seetin MG, Mathews DH. 2011. Automated RNA tertiary structure prediction from secondary structure and low-resolution restraints. J Comput Chem 32: 2232-2244.

Shankar N, Kennedy SD, Chen G, Krugh TR, Turner DH. 2006. The NMR structure of an internal loop from $23 \mathrm{~S}$ ribosomal RNA differs from its structure in crystals of 50s ribosomal subunits. Biochemistry 45: 11776-11789.

Shankar N, Xia T, Kennedy SD, Krugh TR, Mathews DH, Turner DH. 2007. NMR reveals the absence of hydrogen bonding in adjacent 
$\mathrm{UU}$ and $\mathrm{AG}$ mismatches in an isolated internal loop from ribosomal RNA. Biochemistry 46: 12665-12678.

Siegfried NA, Kierzek R, Bevilacqua PC. 2010. Role of unsatisfied hydrogen bond acceptors in RNA energetics and specificity. J Am Chem Soc 132: 5342-5344.

Smallcombe SH. 1993. Solvent suppression with symmetrically-shifted pulses. J Am Chem Soc 115: 4776-4785.

Stawinski J, Strömberg R, Thelin M, Westman E. 1988. Studies on the t-butyldimethylsilyl group as 2'-O-protection in oligoribonucleotide synthesis via the $\mathrm{H}$-phosphonate approach. Nucleic Acids Res 16: 9285-9298.

Sugimoto N, Tomka M, Kierzek R, Bevilacqua PC, Turner DH. 1989. Effects of substrate structure on the kinetics of circle opening reactions of the self-splicing intervening sequence from Tetrahymena thermophila: evidence for substrate and $\mathrm{Mg}^{2+}$ binding interactions. Nucleic Acids Res 17: 355-371.

Tan RKZ, Petrov AS, Harvey SC. 2006. YUP: A molecular simulation program for coarse-grained and multiscaled models. J Chem Theory Comput 2: 529-540.

Tolbert BS, Kennedy SD, Schroeder SJ, Krugh TR, Turner DH. 2007. NMR structures of (rGCUGAGGCU) ${ }_{2}$ and (rGCGGAUGCU) ${ }_{2}$ : probing the structural features that shape the thermodynamic stability of GA pairs. Biochemistry 46: 1511-1522.

Turner DH. 2000. Conformational changes. In Nucleic acids: Structures, properties and functions (ed. VA Bloomfield et al.). University Science Press, Sausalito, CA.

Usman N, Ogilvie KK, Jiang MY, Cedergren RJ. 1987. Automated chemical synthesis of long oligoribonucleotides using 2'-O-silylated ribonucleoside $3^{\prime}$-O-phosphoramidites on a controlled-pore glass support: Synthesis of a 43-nucleotide sequence similar to the 3'-half molecule of an Escherichia coli formylmethionine tRNA. J Am Chem Soc 109: 7845-7854.

Varani G, Aboul-ela F, Allain FH-T. 1996. NMR investigation of RNA structure. Prog Nucl Magn Reson Spectrosc 29: 51-128.

Watts JM, Dang KK, Gorelick RJ, Leonard CW, Bess JW Jr, Swanstrom R, Burch CL, Weeks KM. 2009. Architecture and secondary structure of an entire HIV-1 RNA genome. Nature 460: 711-716.
Weixlbaumer A, Jin H, Neubauer C, Voorhees RM, Petry S, Kelley AC, Ramakrishnan V. 2008. Insights into translational termination from the structure of RF2 bound to the ribosome. Science 322: 953-956.

Westhof E, Masquida B, Jossinet F. 2010. Predicting and modeling RNA architecture. Cold Spring Harb Perspect Biol doi: 10.1101/ cshperspect.a003632.

Wijmenga SS, Kruithof M, Hilbers CW. 1997. Analysis of (1)H chemical shifts in DNA: Assessment of the reliability of (1) H chemical shift calculations for use in structure refinement. $J$ Biol NMR 10: 337-350.

Wild K, Weichenrieder O, Leonard GA, Cusack S. 1999. The 2 A structure of helix 6 of the human signal recognition particle RNA. Structure 7: 1345-1352.

Wincott F, Direnzo A, Shaffer C, Grimm S, Tracz D, Workman C, Sweedler D, Gonzalez C, Scaringe S, Usman N. 1995. Synthesis, deprotection, analysis and purification of RNA and ribozymes. Nucleic Acids Res 23: 2677-2684.

Wu M, Turner DH. 1996. Solution structure of (rGCGGACGC) $)_{2}$ by two-dimensional NMR and the iterative relaxation matrix approach. Biochemistry 35: 9677-9689.

Xia T, SantaLucia J Jr, Burkard ME, Kierzek R, Schroeder SJ, Jiao X, Cox C, Turner DH. 1998. Thermodynamic parameters for an expanded nearest-neighbor model for formation of RNA duplexes with Watson-Crick base pairs. Biochemistry 37: 14719-14735.

Yang H, Jossinet F, Leontis N, Chen L, Westbrook J, Berman H, Westhof E. 2003. Tools for the automatic identification and classification of RNA base pairs. Nucleic Acids Res 31: 3450-3460.

Yang S, Parisien M, Major F, Roux B. 2010. RNA structure determination using SAXS data. J Phys Chem B 114: 10039-10048.

Yildirim I, Stern HA, Kennedy SD, Tubbs JD, Turner DH. 2010. Reparameterization of RNA chi torsion parameters for the AMBER force field and comparison to NMR spectra for cytidine and uridine. J Chem Theory Comput 6: 1520-1531.

Znosko BM, Burkard ME, Schroeder SJ, Krugh TR, Turner DH. 2002. Sheared $\mathrm{A}_{\text {anti }} \cdot \mathrm{A}_{\text {anti }}$ base pairs in a destabilizing $2 \times 2$ internal loop: the NMR structure of $5^{\prime}(\text { rGGCAAGCCU })_{2}$. Biochemistry 41: 14969-14977. 

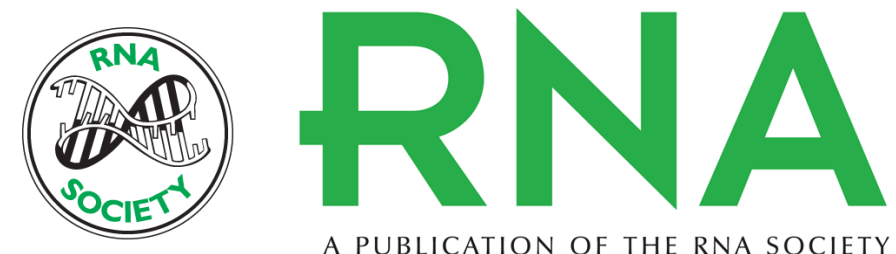

A PUBLICATION OF THE RNA SOCIETY

\section{NMR structure of a $4 \times 4$ nucleotide RNA internal loop from an R2 retrotransposon: Identification of a three purine-purine sheared pair motif and comparison to MC-SYM predictions}

Yelena V. Lerman, Scott D. Kennedy, Neelaabh Shankar, et al.

RNA 2011 17: 1664-1677 originally published online July 21, 2011

Access the most recent version at doi:10.1261/rna.2641911

Supplemental Material

References

License

Email Alerting Service
http://rnajournal.cshlp.org/content/suppl/2011/07/21/rna.2641911.DC1

This article cites 105 articles, 19 of which can be accessed free at: http://rnajournal.cshlp.org/content/17/9/1664.full.html\#ref-list-1

Receive free email alerts when new articles cite this article - sign up in the box at the top right corner of the article or click here. 